Research Article

\title{
Comprehensive Screening and Identification of Phillyrin Metabolites in Rats Based on UHPLC-Q-Exactive Mass Spectrometry Combined with Multi-Channel Data Mining
}

\author{
Beibei Ma (iD), ${ }^{1}$ Jiameng Li, ${ }^{1}$ Tianyu Lou, ${ }^{1}$ Yaoyue Liang, ${ }^{1}$ Chenxiao Wang, ${ }^{1}$ Ruiji Li, ${ }^{1}$ \\ Tingting Wang, ${ }^{1}$ Jinhui Liu, ${ }^{1}$ Yudong Guo, ${ }^{2}$ Zhibin Wang $\mathbb{D}^{3},{ }^{3}$ and Jing Wang ${ }^{1}{ }^{1}$ \\ ${ }^{1}$ School of Chinese Pharmacy, Beijing University of Chinese Medicine, Beijing, China \\ ${ }^{2}$ Beijing Institute for Drug Control, Beijing, China \\ ${ }^{3}$ Beijing Research Institution of Chinese Medicine, Beijing University of Chinese Medicine, Beijing, China
}

Correspondence should be addressed to Zhibin Wang; wangzhibin4804@126.com and Jing Wang; crystal_wj@163.com

Received 3 January 2020; Revised 8 March 2020; Accepted 30 March 2020; Published 24 June 2020

Academic Editor: Barbara Bojko Copyright (c) 2020 Beibei Ma et al. This is an open access article distributed under the Creative Commons Attribution License, which
permits unrestricted use, distribution, and reproduction in any medium, provided the original work is properly cited.

Phillyrin, a well-known bisepoxylignan, has been shown to have many critical pharmacological activities. In this study, a novel strategy for the extensive acquisition and use of data was established based on UHPLC-Q-Exactive mass spectrometry to analyze and identify the in vivo metabolites of phillyrin and to elucidate the in vivo metabolic pathways of phillyrin. Among them, the generation of data sets was mainly due to multichannel data mining methods, such as high extracted ion chromatogram (HEIC), diagnostic product ion (DPI), and neutral loss filtering (NLF). A total of 60 metabolites (including the prototype compound) were identified in positive and negative ion modes based on intuitive and useful data such as the standard's cleavage rule, accurate molecular mass, and chromatographic retention time. The results showed that a series of biological reactions of phillyrin in vivo mainly included methylation, hydroxylation, hydrogenation, sulfonation, glucuronidation, demethylation, and dehydrogenation and their composite reactions. In summary, this study not only comprehensively explained the in vivo metabolism of phillyrin, but also proposed an effective strategy to quickly analyze and identify the metabolites of natural pharmaceutical ingredients in nature.

\section{Introduction}

Phillyrin, as an essential bisepoxylignan, is the main component of Forsythia suspensa (Thunb.) Vahl in plants belongs to the family Oleaceae [1-3]. Modern pharmacological research has shown that phillyrin not only has potent biological activity, but also plays a huge role that cannot be ignored in resisting diseases and maintaining human health, such as inhibiting inflammatory response, antiviral, antioxidative stress, and anticell apoptosis [4-8]. Phillyrin has been reported to improve insulin resistance in the body $[9,10]$, and it can also reduce the weight of obese mice through specific pathways [11]. Besides, phillyrin can decrease the formation and function of osteoclasts and prevent LPS-induced osteolysis in mice [12]. However, there are still many deficiencies in the comprehensive research on phillyrin metabolism in vivo. Therefore, revealing the metabolites and metabolic pathways of phillyrin is of great significance for its further development and utilization.

As we all know, liquid chromatography-mass spectrometry (LC-MS) combines the high separation power of liquid chromatography with the forceful qualitative and quantitative ability of mass spectrometry, which has the advantages of high sensitivity, high selectivity, and rich structural information [13-15]. UHPLC-Q-Exactive MS (ultra high-performance liquid chromatography coupled with hybrid quadrupole-Orbitrap mass spectrometry) can thoroughly and extensively obtain the structural information of compounds by using the functions of positive and negative ion scanning mode, full scanning, and automatic triggering of secondary mass spectrometry scanning. The superior resolution based on Orbitrap technology can quickly achieve the measurement of high-accuracy mass. Therefore, it can identify and confirm small molecule 
compounds in mixtures, is a powerful tool for analyzing complex compound systems, and has been extensively used in compound identification and screening [16-18]. By obtaining sufficient fragment information and analyzing composition information of a compound online, the molecular weight of the compound can be determined, and the possible molecular structure can be inferred based on the primary, secondary, and even multilevel mass spectral information [19-21]. In consequence, it is imperative to form a comprehensive and authoritative data set in the data processing process. Data mining methods reported in recent years have emerged endlessly, mainly including the following categories: mass defect filter, extracted ion chromatogram, diagnostic product ion (DPI), neutral loss filtering (NLF), and isotope pattern filtering [22-27].

In this paper, we have established a new strategy that combined UHPLC-Q-Exactive MS with multiple data mining analysis methods. Due to its slight detection limit and narrow deviation range, it is feasible to analyze and identify metabolites in rats for oral administration of phillyrin. Based on this study, we further proposed the in vivo metabolic pathways of phillyrin, which made up for the shortcomings of the current insufficient research on phillyrin metabolism and was conducive to revealing the in vivo mechanism of many pharmacological activities of phillyrin.

\section{Materials and Methods}

Based on the previous research results of our research group, we adopted the experimental methods and sample processing procedures of our predecessors [28, 29].

2.1. Chemicals and Reagents. The reference standard of phillyrin was purchased from Chengdu Must Biotechnology Co. Ltd. (Sichuan, China). After HPLC-UV analysis, the purity of phillyrin was not less than 98\%. Acetonitrile, methanol, and formic acid (HPLC grade) used in the mobile phase were provided by Fisher Scientific (Fair Lawn, NJ, USA). C18-low solid-phase extraction (SPE) cartridges (3 L/ $60 \mathrm{~g}$ ) for biological sample pretreatment were obtained from Waters (Milford, MA, USA). Ultrapure water was freshly prepared using the Milli-Q Gradient $\AA 10$ water purification system (Millipore, Billerica, MA, USA). Moreover, other reagents and solvents met the requirements of analytical experiments in Beijing Chemical Works (Beijing, China).

2.2. Animals and Drug Administration. Sixteen male SD rats weighing 200-220 g were purchased from Beijing Weitong Lihua Experimental Animals Company (Beijing, China). All animals were kept under specific environmental conditions (temperature $22 \pm 1^{\circ} \mathrm{C}$, humidity $60 \pm 10 \%, 12$-hour day and night change), with free access to food and water for one week. The rats were then randomly divided into Drug Group (for experimental urine, plasma and feces, $n=8$ ) and Control Group (for blank urine, plasma, and feces, $n=8$ ). The reference standard of phillyrin was suspended in $0.5 \%$ sodium carboxymethyl cellulose (CMC-Na) solution. The Drug Group was orally administered phillyrin $(300 \mathrm{mg} / \mathrm{kg})$, while Control Group was given an equal amount of $0.5 \%$ CMC-Na solution by oral gavage. All animals were fasted for 12 hours before the experiment but had free access to water. The experimental protocol has been approved by the institutional Animal Care and Use Committee in Beijing University of Chinese Medicine. All procedures were carried out according to the Guide for the Care and Use of Laboratory Animals of the US National Institutes of Health.

\subsection{Sample Collection}

2.3.1. Plasma Sample Collection. After oral administration, all rats were placed in metabolic cages. Blood samples (about $0.5 \mathrm{ml}$ ) were taken from the infraorbital venous plexus of rats at time points of $0.5,1,1.5,2$, and $4 \mathrm{~h}$ after administration, and the operation was identical for each rat. Blank and experimental samples were obtained from the Control Group and the Drug Group, respectively. All blood samples were placed in a heparin sodium anticoagulated EP tube for 15 minutes and then centrifuged at $3000 \mathrm{rpm}\left(4^{\circ} \mathrm{C}\right)$ for 15 minutes to separate plasma. After that, the plasma from the same group was combined into an aggregate and stored at $-80^{\circ} \mathrm{C}$ until use.

2.3.2. Urine Sample Collection. Urine samples (0-24 h) were collected from each rat using a metabolic cage, and each sample was centrifuged at $3000 \mathrm{rpm}\left(4^{\circ} \mathrm{C}\right)$ for $15 \mathrm{~min}$ to obtain a supernatant. The urine supernatants of each group of rats were mixed and stored at $-80^{\circ} \mathrm{C}$ until use.

2.3.3. Feces Sample Collection. Fecal samples (0-24h) were obtained from each rat using a metabolic cage, then dried, and ground to a powder. The fecal powders of each group of rats were mixed. Firstly, $0.5 \mathrm{~g}$ of fecal powder was dissolved in $70 \%$ methanol, and then it was extracted for $30 \mathrm{~min}$ by ultrasonic. Finally, fecal samples of rats in the Control Group and the Drug Group were obtained.

2.4. Biological Sample Preparation. All biological samples were prepared by precipitating and concentrating proteins and solid residues. Firstly, the SPE cartridges were pretreated by activation with methanol $(5 \mathrm{ml})$ and deionized water (5 ml). Afterward, plasma, urine, and feces samples $(1 \mathrm{ml})$ were added to the SPE cartridges, respectively. Then, the SPE cartridges were eluted with deionized water $(5 \mathrm{ml})$ and methanol $(3 \mathrm{ml})$ in that order, and the methanol eluates were collected. Finally, the eluates were dried with nitrogen at room temperature, and the residue was redissolved in 5\% acetonitrile solution $(100 \mu \mathrm{l})$ and centrifuged at $14000 \mathrm{rpm}$ $\left(4^{\circ} \mathrm{C}\right)$ for $15 \mathrm{~min}$. The supernatant obtained by the above method was used for instrumental analysis.

2.5. Instruments and Conditions. All biological samples were analyzed using a UHPLC-Q-Exactive mass spectrometer (Thermo Fisher Scientific, MA, USA) equipped with an ESI ion source. Chromatographic separation was performed on a Waters ACQUITY BEH C18 column 
$(2.1 \mathrm{~mm} \times 100 \mathrm{~mm} \times 1.7 \mu \mathrm{m}$; Waters Corporation, Milford, MA, USA), and the temperature was set at $25^{\circ} \mathrm{C}$. The mobile phase consists of $0.1 \%$ formic acid solution (A) and acetonitrile (B), and the linear gradient was set as follows: $0-1 \mathrm{~min}, 5 \% \mathrm{~B}$; $1-3 \mathrm{~min}, 5 \%-25 \% \mathrm{~B}$; 3-8 min, 25\%-60\% B; $8-15 \mathrm{~min}, \quad 60 \%-80 \% \mathrm{~B} ; \quad 15-20 \mathrm{~min}, \quad 80 \%-100 \% \quad \mathrm{~B}$; 20-24 min, $100 \% \mathrm{~B} ; \quad 24-25 \mathrm{~min}, 100 \%-5 \% \mathrm{~B}$; and $25-30 \mathrm{~min}, 5 \% \mathrm{~B}$. The flow rate was $0.3 \mathrm{~mL} / \mathrm{min}$ and the injection volume was $2 \mu \mathrm{L}$.

The optimal operating parameters in negative and positive ion mode were set as follows: electrospray voltage, $4 \mathrm{kV}$; capillary temperature, $350^{\circ} \mathrm{C}$; sheath gas flow rate, $275 \mathrm{kPa}$; auxiliary gas flow rate, $138 \mathrm{kPa}$; auxiliary gas temperature, $300^{\circ} \mathrm{C}$; and collision energy, $40 \mathrm{eV}$. Metabolites were detected from $\mathrm{m} / \mathrm{z}$ 100-1500 using full-scan mass spectrometry with a resolution of 70000 . Furthermore, the acquisition mode that relies on the parent ion list- (PIL-) DE was used to obtain the $\mathrm{MS}^{n}$ phase of the acquired data set.

2.6. Data Processing. A Thermo Xcalibur 2.1 workstation (Thermo Scientific, Bremen, Germany) was utilized to acquire and process HR-ESI-MS ${ }^{1}$ and MS $^{n}$ data. Based on the established screening templates of metabolites, by searching the metabolites with specific molecular weight to compare the high-resolution extracted ion chromatograms of the Control Group and the Drug Group, the metabolites related to phillyrin were selected. To obtain as many phillyrin metabolite ions as possible, the peaks detected with intensity over 10,000 for negative ion mode and 50,000 for positive ion mode were selected for further structural characterization. Based on the exact mass of the metabolite and the set elemental composition, the formula predictor could accurately calculate the chemical formula of all parent ions. The type and number of atoms were set as follows: $\mathrm{C}$ [0-40], $\mathrm{H}$ [0-60], O [0-25], S [0-2], N [0-5], and ring double bond (RDB) equivalent value [0-15]. At the same time, MetWorks (Version 1.3) and Mass Frontier (Version 8.0) software (Thermo Scientific, Waltham, MA, USA) were used as auxiliary tools for mass fragmentation behaviors analysis and structural identification.

\section{Results and Discussion}

3.1. The Construction of Analysis Strategy. This study constructed an effective new strategy based on UHPLC-QExactive MS for data acquisition combined with multipath data mining to analyze the metabolism of phillyrin in vivo. First of all, the ESI-MS ${ }^{n}$ data set of the samples in both positive and negative ion modes were obtained by using the data-dependent scanning (DDS) acquisition method. Secondly, the common metabolites of phillyrin were determined according to literature reports and HREIC search, thereby establishing the screening templates for phillyrin metabolites. Then, by analyzing the mass fragmentation behaviors of the reference standards, the reasonable DPIs and NLFs of phillyrin were summarized. Afterward, based on the chromatographic retention time, the established DPIs and NLFs, and the corresponding calculated ClogP values, the structure of a series of metabolites of phillyrin could be identified. Finally, the metabolic pathway of phillyrin can be inferred from the above metabolic data. The entire research process of this strategy is shown in Figure 1.

\subsection{Establishment of the Screening Templates for Metabolites.} According to literature reports and HREICs search, three compounds (phillyrin, phillygenin, and enterolactone) were selected as primary metabolites, which are often found in the metabolites of phillyrin. After data sorting, in negative ion mode, the metabolites screening templates were set as follows: (1) phillyrin template $(\mathrm{m} / z$ 533.2017); (2) phillygenin template $(\mathrm{m} / \mathrm{z} 371.1489)$ and its derivative templates $(\mathrm{m} / z$ 329.1020 for detrimethyl, $m / z 357.1333$ for demethylation, $\mathrm{m} / z 373.1646$ for hydrogenation, and $\mathrm{m} / z 387.1438$ for oxygenation); (3) enterolactone template $(\mathrm{m} / \mathrm{z} 297.1121)$. Based on this effective method, some nondiscoverable metabolites could also be screened out from complex background noise.

3.3. Analysis of Mass Fragmentation Behavior of Phillyrin. To further explore the ESI-MS ${ }^{n}$ fracture behavior of phillyrin, a comprehensive analysis of the standard solution was performed using UHPLC-Q-Exactive MS. For example, phillyrin in negative ion mode could find $[\mathrm{M}+\mathrm{HCOOH}-\mathrm{H}]^{-}$ion at $m / z 579.2072$ in the ESI-MS ${ }^{1}$ spectrum. Due to the absence of the glucose fragment, its characteristic ion peak was found at $\mathrm{m} / z 371$ of the ESI-MS ${ }^{2}$ spectrum. On this basis, several series of characteristic product ions were retrieved at $m / z 357, m / z 341, m / z 327$, and $m / z 311$ because a series of fragments such as $\mathrm{CH}_{2}$, $2 \mathrm{CH}_{2}, \mathrm{CH}_{2}+\mathrm{CH}_{2} \mathrm{O}$, and $2 \mathrm{CH}_{2} \mathrm{O}$ were successively lost. Compounds with the same parent nucleus will have similar cleavage fragments in the ESI-MS ${ }^{n}$ spectrum, so a comprehensive identification of metabolites can be achieved based on regular DPIs and NLFs. For example, the DPI at $\mathrm{m} /$ $z 371$ was diagnosed due to the absence of a glucose moiety. Thus the presence of DPIs at $\mathrm{m} / z 371$ or $\mathrm{m} / z 371+\mathrm{X}$ in the ESI-MS ${ }^{2}$ spectrum of the compound provided comparable information for the identification of metabolites. At the same time, the continuous appearance of $14 \mathrm{Da}\left(\mathrm{CH}_{2}\right)$ and $30 \mathrm{Da}\left(\mathrm{CH}_{2} \mathrm{O}\right)$ NLFs in the ESI-MS ${ }^{n}$ spectrum of phillyrin also provided significant help for the identification of metabolites. The cleavage pathway of phillyrin in negative ion mode is presented in Figure 2. Moreover, the mass fragmentation behaviors of phillyrin in positive ion mode are shown in Figure 3.

3.4. Identification of Phillyrin Metabolites in Rats. The total ion chromatograms (TICs) of urine, plasma, and feces samples after oral administration of phillyrin in rats were obtained using UHPLC-Q-Exactive mass spectrometry. A total of 60 metabolites were found in both positive and negative ion modes by processing the data collected from the UHPLC-Q-Exactive instrument. Among them, there were 31 metabolites in positive ion mode and 33 metabolites in negative ion mode. In addition, after the literature search 


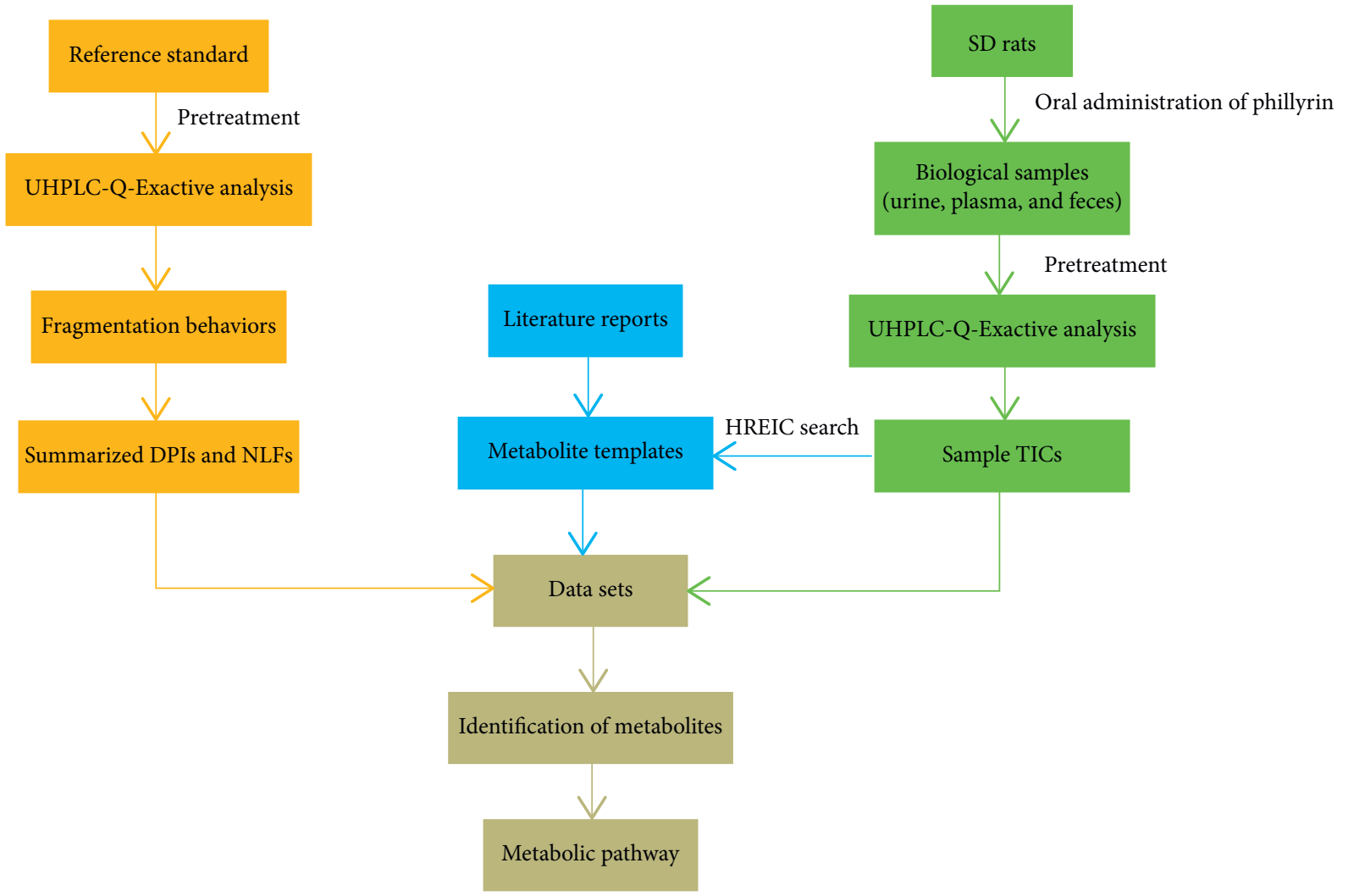

FIgURE 1: Summary diagram of the developed strategy and methodology.

and comparison, 21 metabolites have been found and detected by predecessors [30, 31], while the remaining 39 metabolites have been screened and identified through the established strategy. All relevant mass spectral data are summarized in Table 1, and high-resolution extracted ion chromatograms (HREICs) of all metabolites of phillyrin are shown in Figure 4.

\subsubsection{Identification of Metabolites Based on Phillyrin.} The metabolite $\mathrm{M} 0$ producing $[\mathrm{M}+\mathrm{HCOOH}-\mathrm{H}]^{-}$ion at $\mathrm{m} / z$ $579.2072\left(\mathrm{C}_{28} \mathrm{H}_{35} \mathrm{O}_{13}, 2.32 \mathrm{ppm}\right)$ was eluted at $6.60 \mathrm{~min}$. In contrast to the elution time and fragmentation behavior of the phillyrin standard, $\mathrm{M} 0$ could be accurately inferred as the phillyrin $[32,33]$.

The retention times of the metabolites M17 and M22 were 5.76 and $5.96 \mathrm{~min}$, respectively, and they showed the same molecular ion at $\mathrm{m} / \mathrm{z} 519.1498 \quad\left(\mathrm{C}_{25} \mathrm{H}_{27} \mathrm{O}_{12}\right.$, error $\leq \pm 2.50 \mathrm{ppm}$ ). In the ESI-MS ${ }^{2}$ spectrum, the DPI at $\mathrm{m} / \mathrm{z}$ 343 was generated due to the loss of $2 \mathrm{CH}_{2}$ by the phillygenin. While $\mathrm{m} / z 519$ was $176 \mathrm{Da}$ larger than the former, it was inferred that $\mathrm{m} / \mathrm{z} 343$ was caused by the absence of the glucuronic acid moiety. Therefore, it was speculated that M17 (Clog $P,-0.41)$ and M22 (Clog $P,-0.39)$ were demethylated and carboxylated metabolites of phillyrin, but the position of glucuronic acid group was different.

The metabolite M32 was eluted at $6.58 \mathrm{~min}$ and showed $[\mathrm{M}-\mathrm{H}]^{-}$ion at $m / z 533.1652\left(\mathrm{C}_{26} \mathrm{H}_{29} \mathrm{O}_{12}, 2.15 \mathrm{ppm}\right)$. Similarly, as in the case of M17, the presence of $\mathrm{m} / \mathrm{z} 175$ meant the formation of glucuronic acid. While M32 was $14 \mathrm{Da}$ higher than M17, it was speculated that the phillygenin only had one molecule of $\mathrm{CH}_{2}$ removed.

The metabolite M36 with a retention time of $6.76 \mathrm{~min}$ showed $[\mathrm{M}-\mathrm{H}]^{-}$ion at $\mathrm{m} / z 547.1809\left(\mathrm{C}_{27} \mathrm{H}_{31} \mathrm{O}_{12}, 2.17 \mathrm{ppm}\right)$. Similar to the above rule, it was concluded that M36 was the carboxylation product of phillyrin.

Metabolite M56 exhibited [M-H $]^{-}$ion at $m / z 507.2225$ $\left(\mathrm{C}_{26} \mathrm{H}_{35} \mathrm{O}_{10}, 2.28 \mathrm{ppm}\right)$. It had a neutral loss of $44 \mathrm{Da}$, $132 \mathrm{Da}$, and $44 \mathrm{Da}$ in the ESI-MS ${ }^{2}$ spectrum, which caused the appearance of $\mathrm{m} / \mathrm{z} 463, \mathrm{~m} / \mathrm{z} 331$, and $\mathrm{m} / \mathrm{z} 287$. Among them, the $44 \mathrm{Da} \mathrm{NLF}$ can be presumed to be $\mathrm{CH}_{2} \mathrm{O}+\mathrm{CH}_{2}$, while the NLF of $132 \mathrm{Da}$ was formed by the loss of $\mathrm{CH}_{2} \mathrm{O}$ from the glucosyl group. Therefore, it was concluded that M56 is the dehydroxylation and hydrogenation product of phillyrin.

3.4.2. Identification of Metabolites Based on Phillygenin. The retention time of the metabolite $\mathrm{M} 44$ was $7.05 \mathrm{~min}$, which showed $[\mathrm{M}+\mathrm{H}]^{+}$ion at $\mathrm{m} / z 305.1772\left(\mathrm{C}_{19} \mathrm{H}_{21} \mathrm{~N}_{4}\right.$, $5.95 \mathrm{ppm})$. According to the DPI at $\mathrm{m} / z 109$ and $\mathrm{m} / z$ 93, it could be inferred that two benzene rings of phillygenin were introduced into $2 \mathrm{NH}_{2}$ and $\mathrm{CH}_{3}$, respectively. Interestingly, $\mathrm{m} / z 205$ was $28 \mathrm{Da}$ higher than $\mathrm{m} / z \mathrm{177}$, and $\mathrm{m} / z 177$ was also 28 Da higher than $\mathrm{m} / z$ 149, so NLF was assumed to be $\mathrm{CH}=\mathrm{NH}$ by molecular formula and degree of unsaturation. Therefore, M44 was presumed to be the ammoniated product of phillygenin.

The metabolite M2 eluted at $2.49 \mathrm{~min}$ showed $[\mathrm{M}-\mathrm{H}]^{-}$ ion at $m / z 315.0865\left(\mathrm{C}_{17} \mathrm{H}_{15} \mathrm{O}_{6},-8.27 \mathrm{ppm}\right)$. In the ESI-MS ${ }^{2}$ 


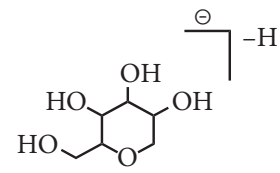

$\mathrm{m} / \mathrm{z} 163$
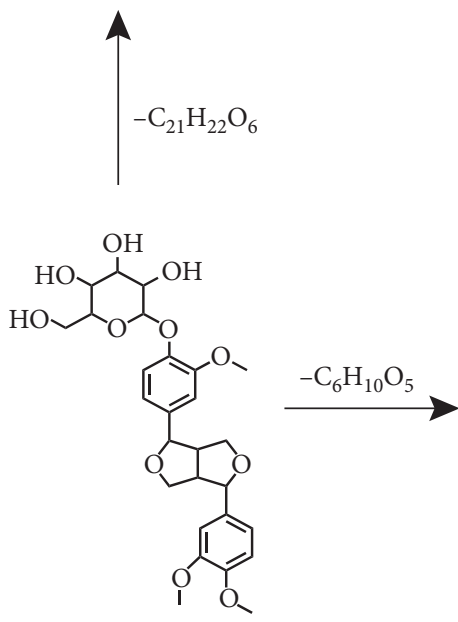

$\left[\mathrm{M}+\mathrm{HCOOH}-\mathrm{H}^{-}\right] \mathrm{m} / \mathrm{z} 579$

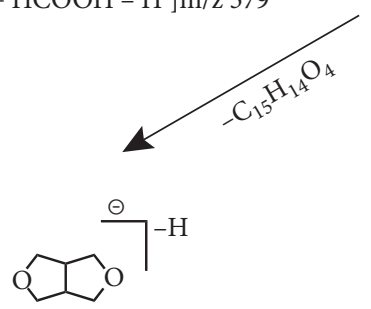

$\mathrm{m} / \mathrm{z} 113$

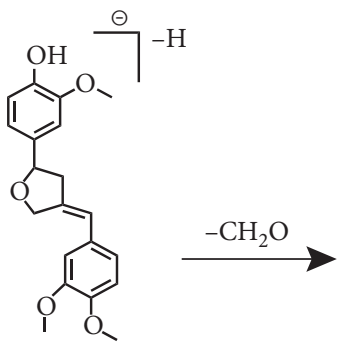

$\mathrm{m} / \mathrm{z} 341$<smiles>CCOCC</smiles>

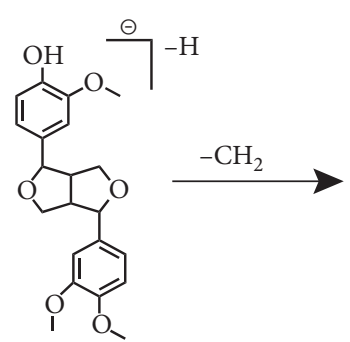

$\mathrm{m} / \mathrm{z} 371$

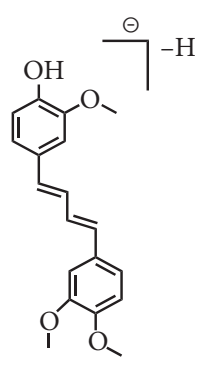

$\mathrm{m} / \mathrm{z} 311$

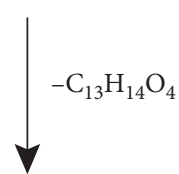

$\mathrm{m} / \mathrm{z} 137$

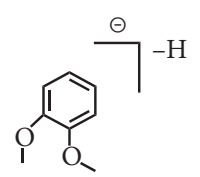

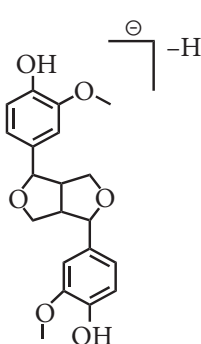

$\mathrm{m} / \mathrm{z} 357$

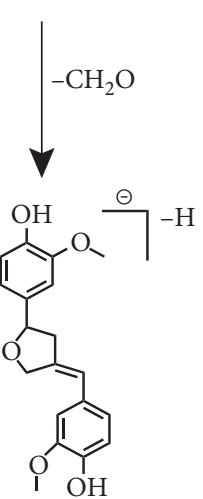

$\mathrm{m} / \mathrm{z} 327$

Figure 2: The fragmentation behavior of phillyrin in negative ion mode.

spectrum, the DPI at $m / z 193$ demonstrated that one of the phenyl rings of the phillygenin was introduced into $4 \mathrm{OH}$, and the mother nucleus lost $2 \mathrm{CH}_{2} \mathrm{O}$. According to the DPI at $\mathrm{m} / z 124,137$, and 150 , the generation of two double bonds could also be proved.

Metabolite M18 was eluted at $5.92 \mathrm{~min}$ and showed $[\mathrm{M}-\mathrm{H}]^{-}$ion at $\mathrm{m} / \mathrm{z} 329.1021\left(\mathrm{C}_{18} \mathrm{H}_{17} \mathrm{O}_{6}, 3.33 \mathrm{ppm}\right)$. The presence of DPI at $m / z 137$ and 163 in the ESI-MS ${ }^{2}$ spectrum confirmed the presence of dimethoxyphenyl, while the DPI at $m / z 109$ speculated that $2 \mathrm{OH}$ was introduced on the other benzene ring. However, the substitution sites of the two other hydroxyl groups could not be determined.

The retention time of the metabolite M39 was $6.79 \mathrm{~min}$, which showed $[\mathrm{M}-\mathrm{H}]$ ions at $m / z 343.1177\left(\mathrm{C}_{19} \mathrm{H}_{19} \mathrm{O}_{6}\right.$,
$3.57 \mathrm{ppm}$ ). Similar to the inferred process of M18, after determining the substituents of two benzene rings, it could be concluded that M39 was the product of the loss of $2 \mathrm{CH}_{2}$ by phillygenin.

Metabolites M38 and M54 eluted at $6.79 \mathrm{~min}$ and $8.44 \mathrm{~min}$, respectively, which showed the same $[\mathrm{M}+\mathrm{H}]^{+}$ion at $\mathrm{m} / \mathrm{z}$ $355.1541\left(\mathrm{C}_{21} \mathrm{H}_{23} \mathrm{O}_{5}\right.$, error $\left.\leq \pm 1.50 \mathrm{ppm}\right)$. The DPI at $\mathrm{m} / z$ 137, 151 indicated the presence of a bismethoxyphenyl group, while $\mathrm{m} / z 189$ was $112 \mathrm{Da}$ higher than $\mathrm{m} / z 77$ (phenyl), inferring the formation of a double bond in the two five-membered rings. Furthermore, $\mathrm{m} / z 284$ was $30 \mathrm{Da}$ higher than $\mathrm{m} / \mathrm{z} 254$, and it was inferred that both were dehydroxyl and dehydrogenated products of phillygenin, except that the position of the double bond was different. 
<smiles>CC[CH]CC</smiles>

$\mathrm{m} / \mathrm{z} 287$<smiles>CCCCCCCCCCCCC</smiles>
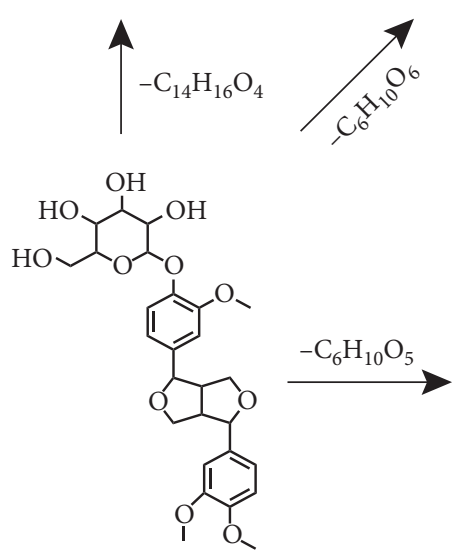

$[\mathrm{M}+\mathrm{Na}]^{+} \mathrm{m} / \mathrm{z} 557$<smiles>CCCCC(C)C</smiles><smiles>OCC1OC(O)=C(O)C(O)C1O</smiles>

$\mathrm{m} / \mathrm{z} 179$

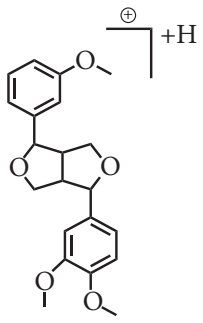

$\mathrm{m} / \mathrm{z} 357$

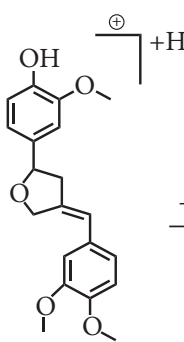

$\mathrm{m} / \mathrm{z} 343$

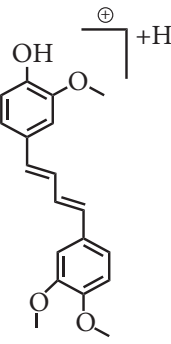

$\mathrm{m} / \mathrm{z} 313$

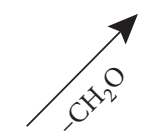<smiles>COc1cc(C2OCC3C(c4ccc(OC)c(OC)c4)COC3c3ccc(OC)c2c3)ccc1O</smiles><smiles>COc1ccc(C2OCC3C(c4ccc(O)c(O)c4)OCC23)cc1OC</smiles><smiles>CC[C+](C)C</smiles>

$\mathrm{m} / \mathrm{z} 359$

$\mathrm{m} / \mathrm{z} 331$

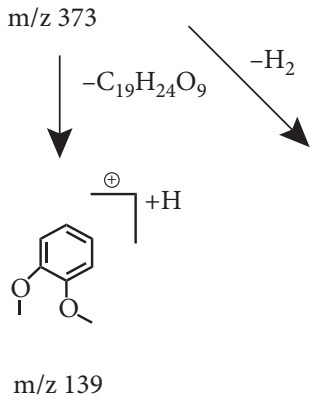

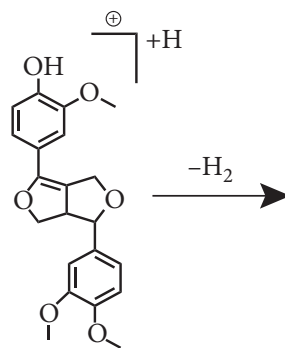

$\mathrm{m} / \mathrm{z} 371$

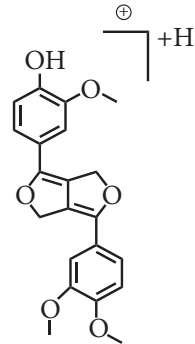

$\mathrm{m} / \mathrm{z} 369$

FIgURE 3: The fragmentation behavior of phillyrin in positive ion mode.

Metabolite M43 was eluted at $6.93 \mathrm{~min}$ and showed $[\mathrm{M}+\mathrm{H}]^{+}$ion at $m / z 371.1489\left(\mathrm{C}_{21} \mathrm{H}_{23} \mathrm{O}_{6},-1.12 \mathrm{ppm}\right)$. It was $2 \mathrm{Da}$ lower than the $[\mathrm{M}+\mathrm{H}]^{+}$ion of phillygenin, and combined with DPIs in the ESI-MS ${ }^{2}$ spectrum, M43 could be identified as the dehydrogenation product of phillygenin.

The metabolite M57 was extracted in HREIC at $\mathrm{m} / \mathrm{z}$ $373.1281\left(\mathrm{C}_{20} \mathrm{H}_{21} \mathrm{O}_{7},-0.99 \mathrm{ppm}\right)$ in positive ion mode with a retention time of $9.65 \mathrm{~min}$. The DPI at $\mathrm{m} / z 373$ was $30 \mathrm{Da}$ higher than $\mathrm{m} / \mathrm{z} 343$, which meant the loss of $\mathrm{CH}_{2} \mathrm{O}$, while $\mathrm{m} / z 343$ was $18 \mathrm{Da}$ higher than $\mathrm{m} / z 325$, indicating that water molecule had been removed. Later, due to the loss of CO NLF, the generation of DPI at $\mathrm{m} / z 297$ was caused. According to this, it could be inferred that after the dehydrogenation and demethylation reaction of the phillygenin, M57 was formed by oxidation. Still, the position of the hydroxyl group could not be determined.

At $6.92 \mathrm{~min}$, the metabolite M42 was eluted, and the $[\mathrm{M}-\mathrm{H}]^{-}$ion was shown at $\mathrm{m} / z 451.1057 \quad\left(\mathrm{C}_{21} \mathrm{H}_{23} \mathrm{O}_{9} \mathrm{~S}\right.$, $3.42 \mathrm{ppm})$. The DPI at $m / z 371$ in the ESI-MS ${ }^{2}$ spectrum can be inferred as phillygenin, and $m / z 451$ was 80 Da higher than $m / z$ 371, which was a great help for us to conclude that M42 is a sulfonated product of phillygenin [30].

The retention time of M33 was $6.59 \mathrm{~min}$, which showed $[\mathrm{M}+\mathrm{H}]^{+}$ion at $m / z 492.1687\left(\mathrm{C}_{24} \mathrm{H}_{30} \mathrm{O}_{8} \mathrm{NS},-1.35 \mathrm{ppm}\right)$. The DPI at $m / z 492$ was $137 \mathrm{Da}$ higher than $\mathrm{m} / z$ 355, and it was presumed that NLF might be a cysteine-oxygen atom $\left(\mathrm{C}_{3} \mathrm{H}_{7} \mathrm{NO}_{2} \mathrm{~S}+\mathrm{O}\right)$. The DPI at $\mathrm{m} / z 88\left(\mathrm{C}_{3} \mathrm{H}_{6} \mathrm{NO}_{2}\right)$ was more potent in demonstrating this so that M33 might be the product of the binding of the phillygenin to cysteine.

The metabolite M58 eluted at $9.90 \mathrm{~min}$ produced $[\mathrm{M}-\mathrm{H}]^{-}$ions at $m / z 261.1146\left(\mathrm{C}_{15} \mathrm{H}_{17} \mathrm{O}_{4}, 4.15 \mathrm{ppm}\right)$. From the ESI-MS ${ }^{2}$ spectrum, the NLF from $\mathrm{m} / z 262$ to $\mathrm{m} / z 235$ might be $\mathrm{CH}=\mathrm{CH}_{2}$. Similarly, the DPI at $\mathrm{m} / z 191$ was due to the loss of $\mathrm{CH}=\mathrm{CH}$ from $\mathrm{m} / z$ 217. Moreover, the reason why the $\mathrm{m} / z 235$ was 18 Da higher than the $\mathrm{m} / z 217$ was that one molecule of water was lost. It was presumed that the glucosyl moiety had undergone a reduction reaction, leaving two hydroxyl groups remaining on the ring. 


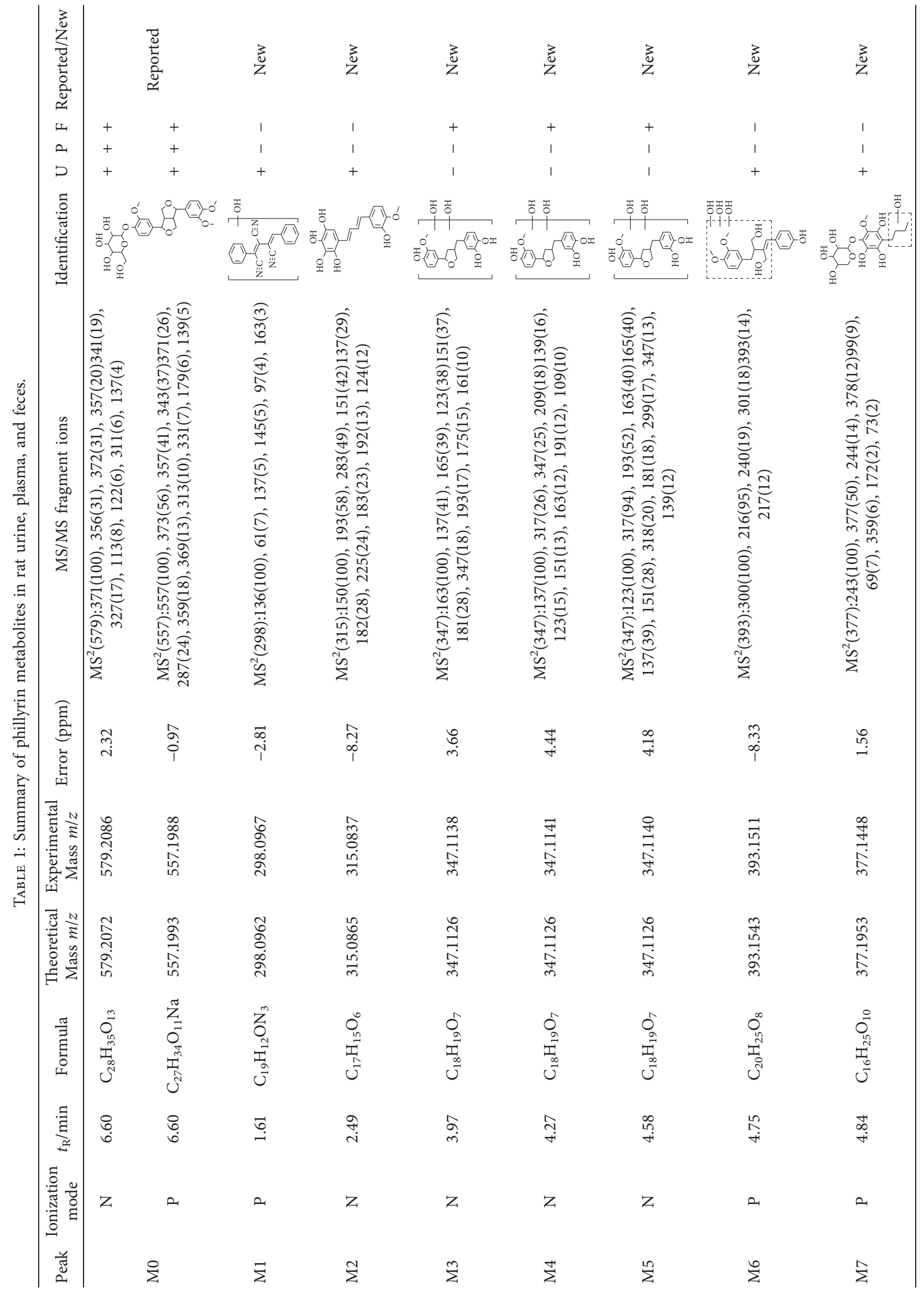




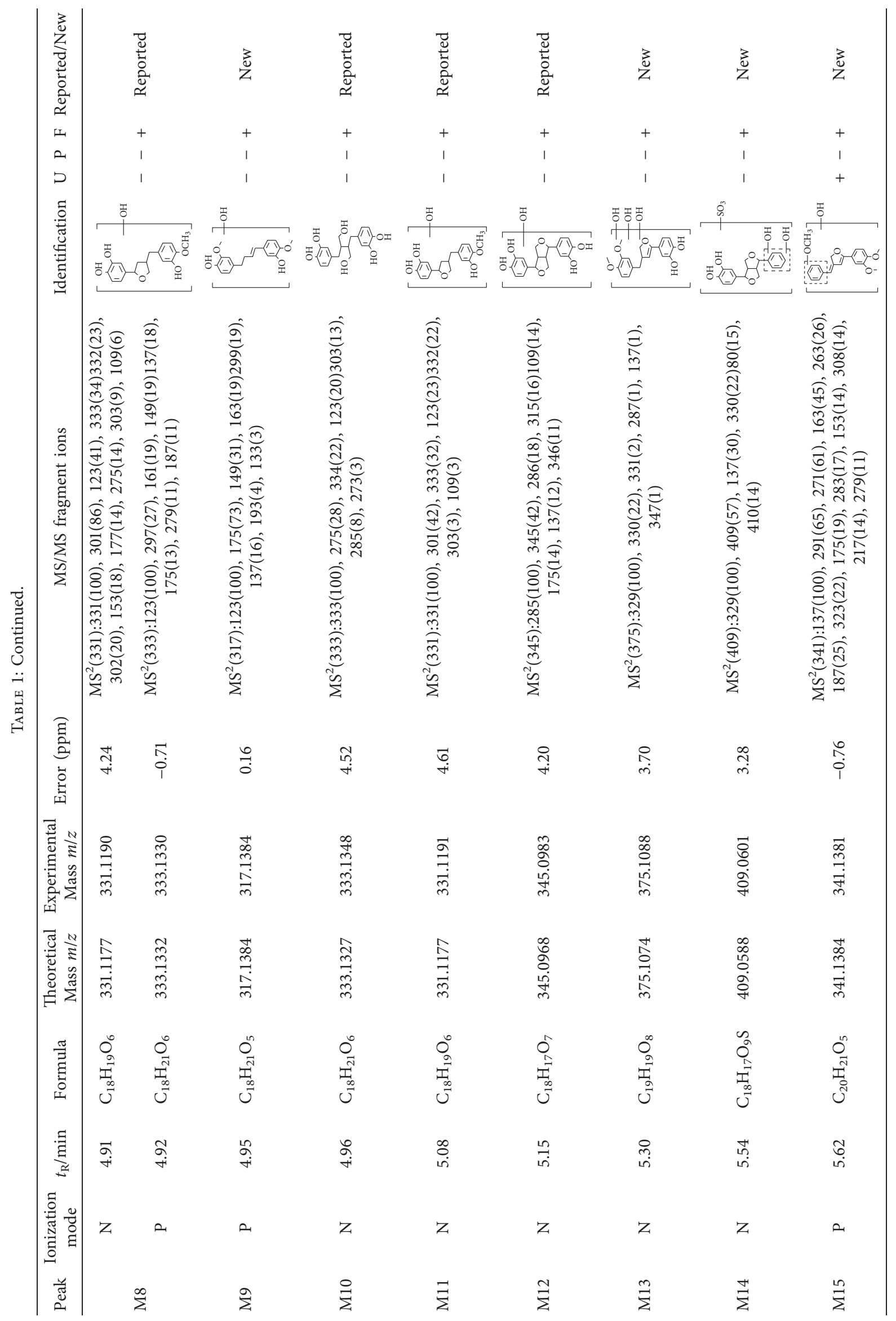




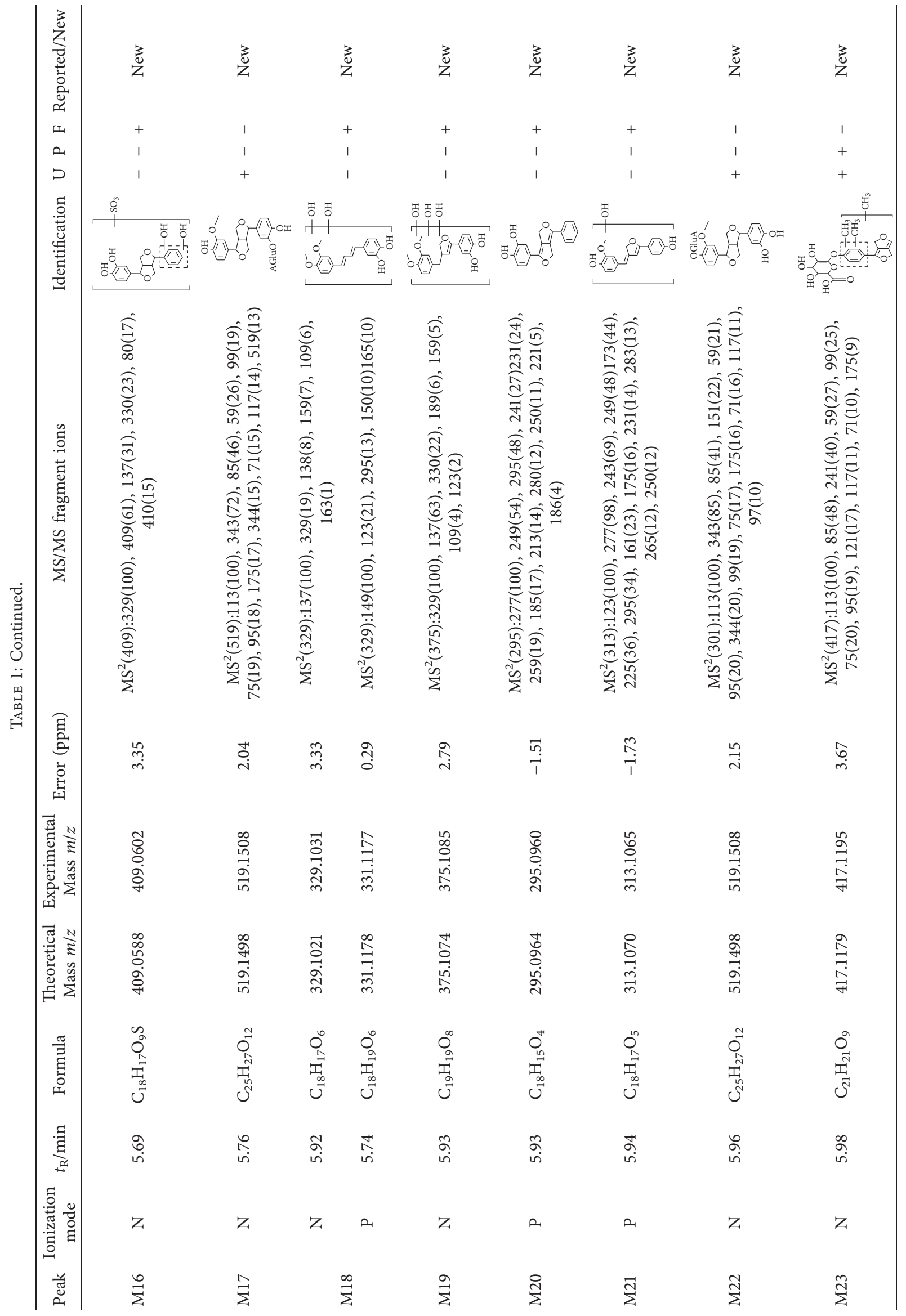




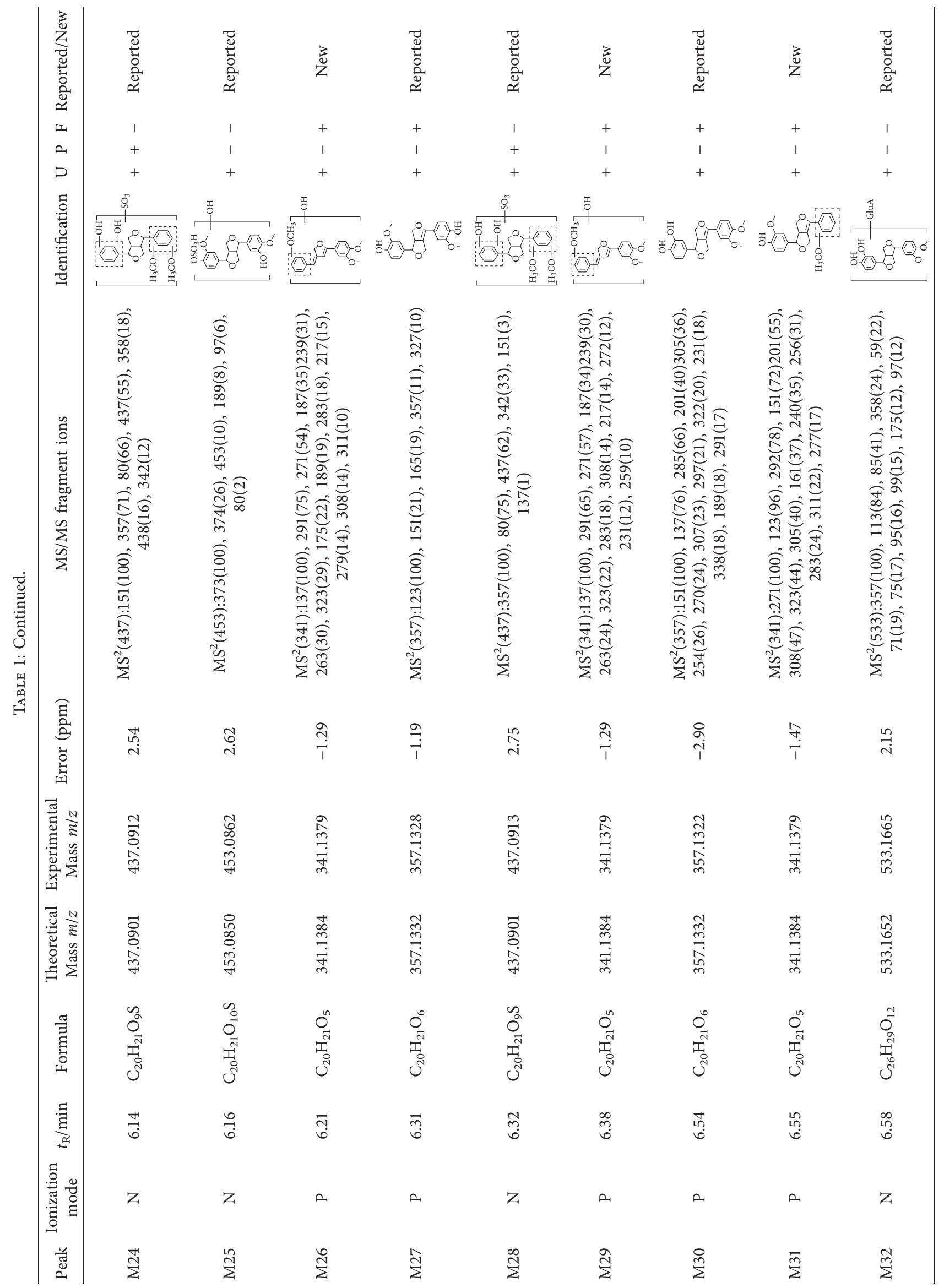




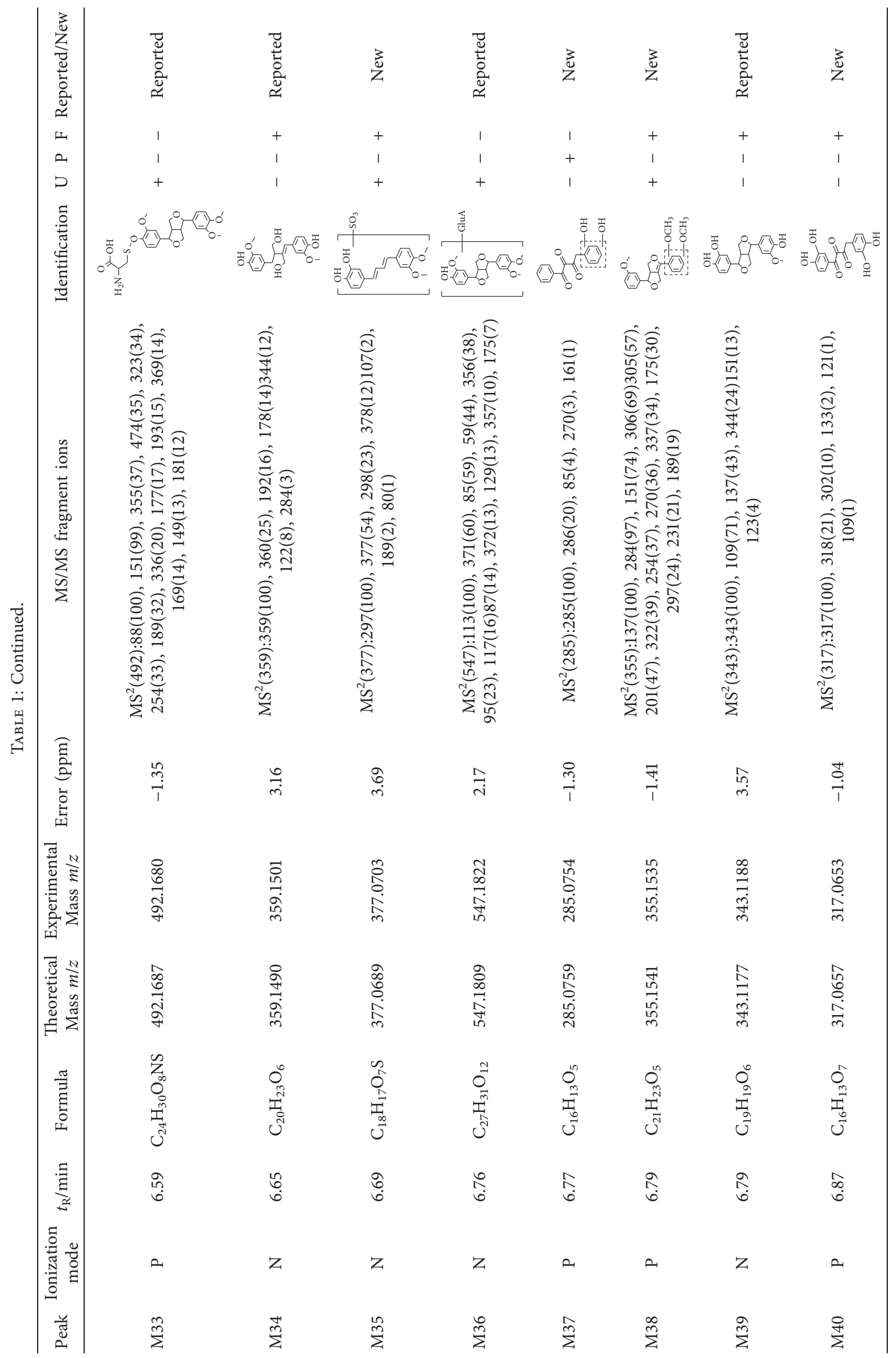




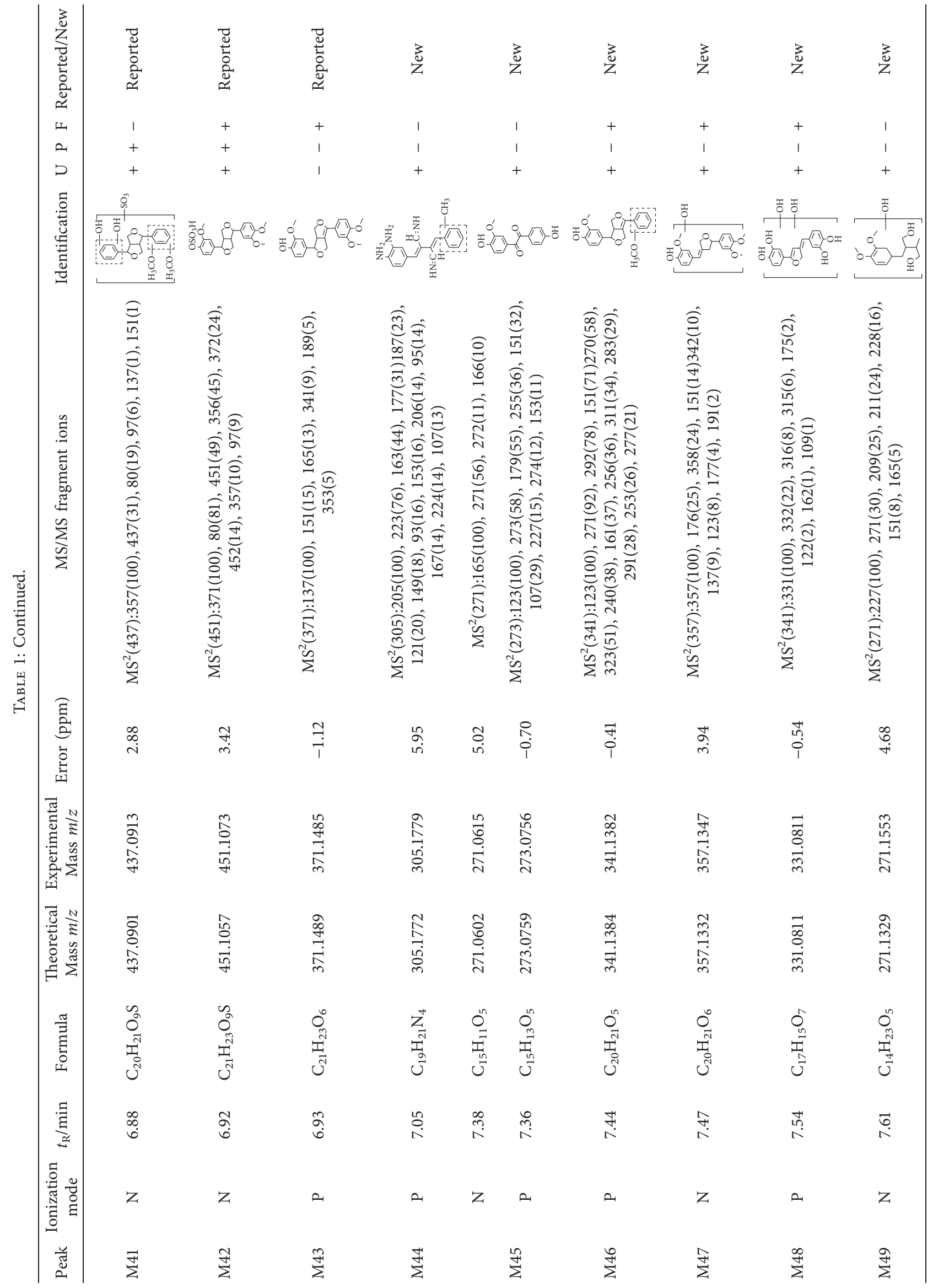




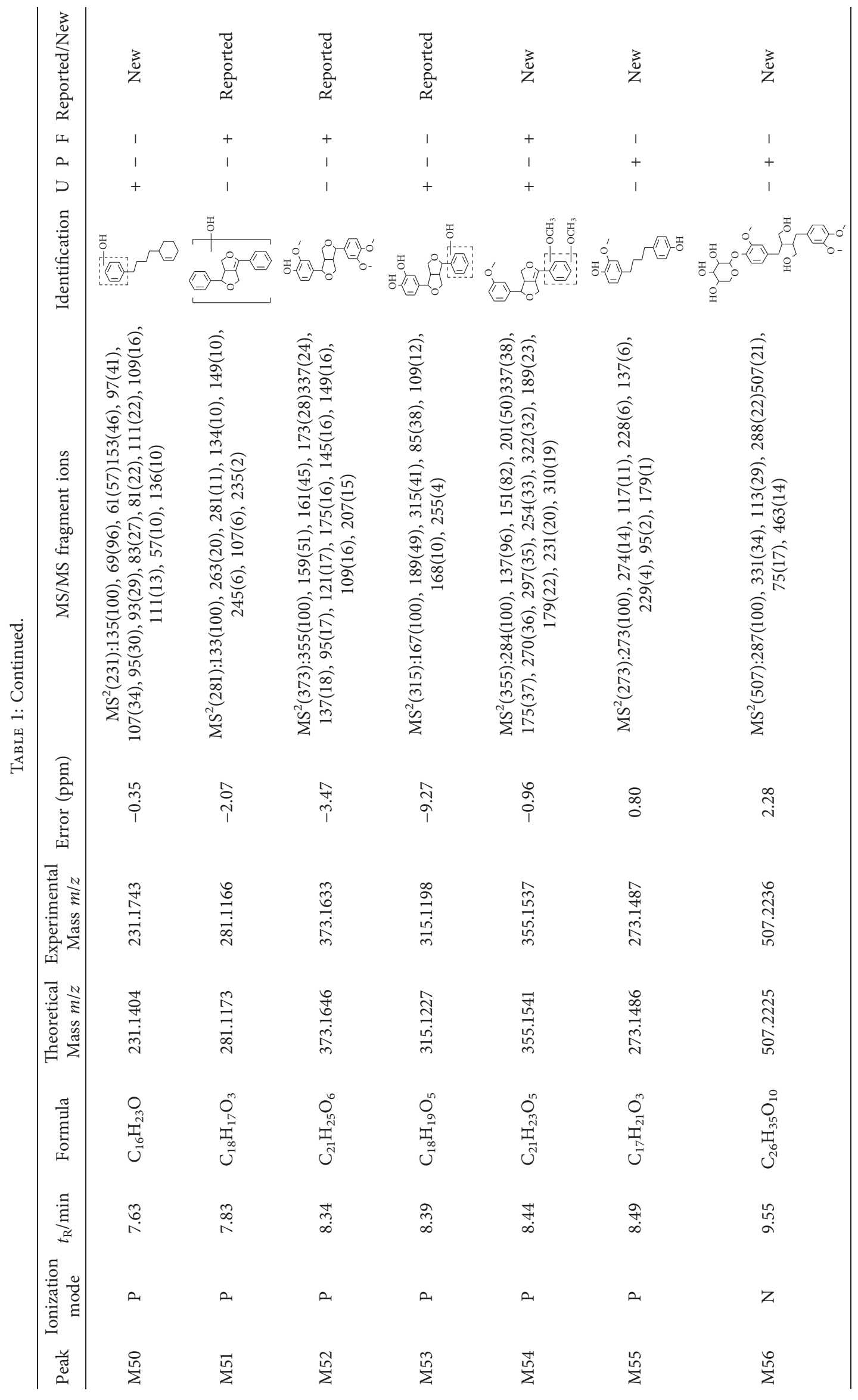




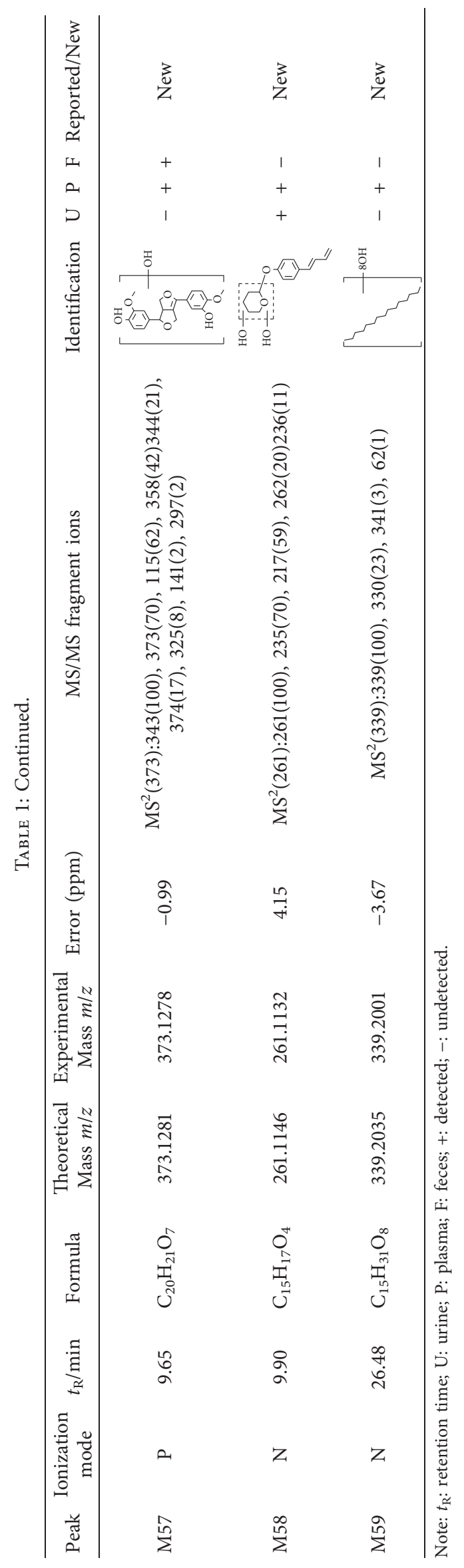




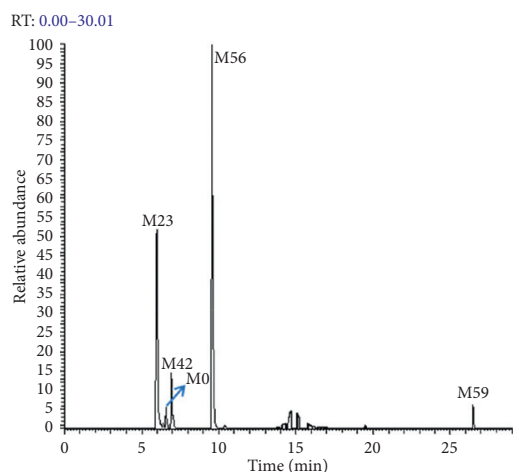

(a)

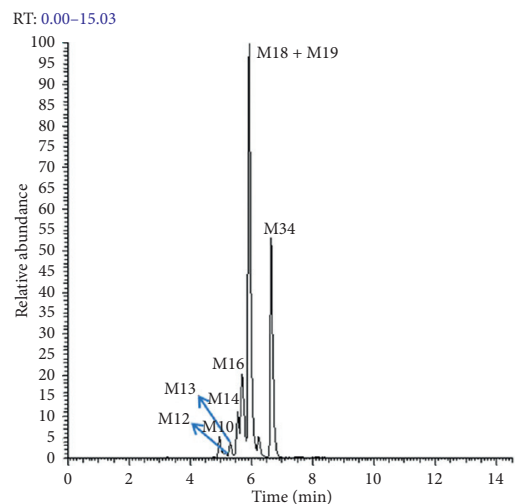

(d)

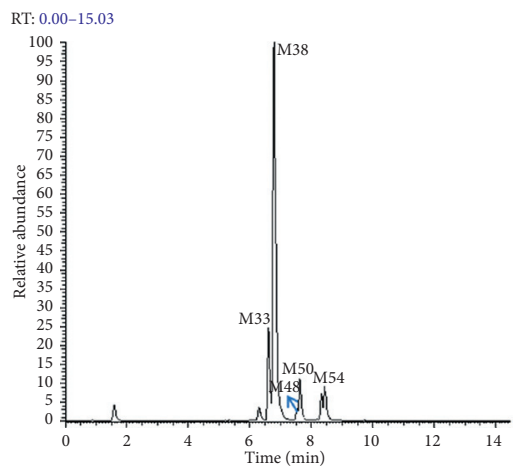

(g)

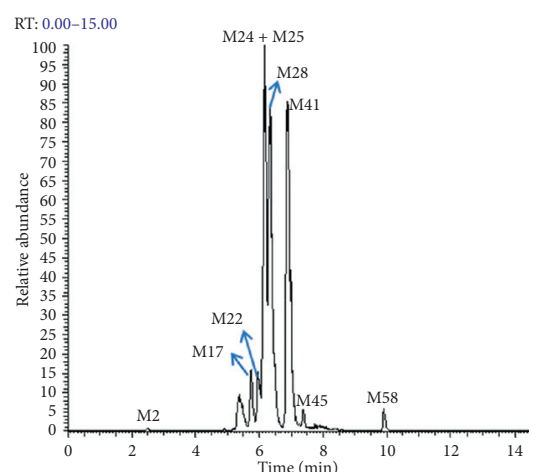

(b)

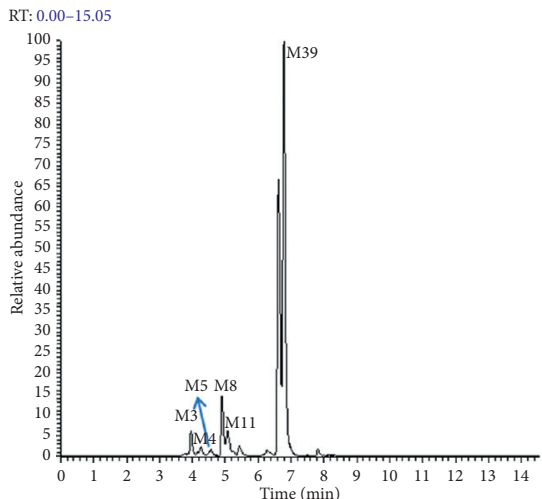

(e)

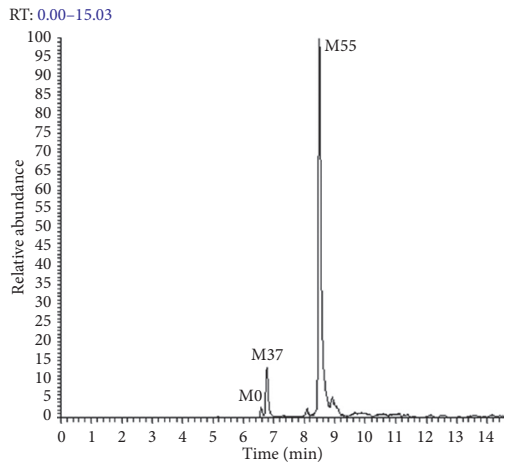

(h)

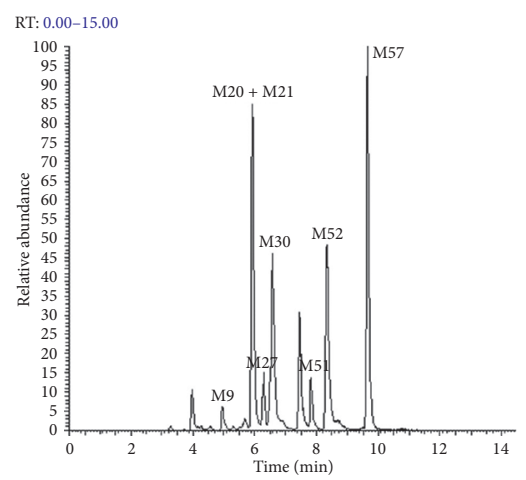

(j)

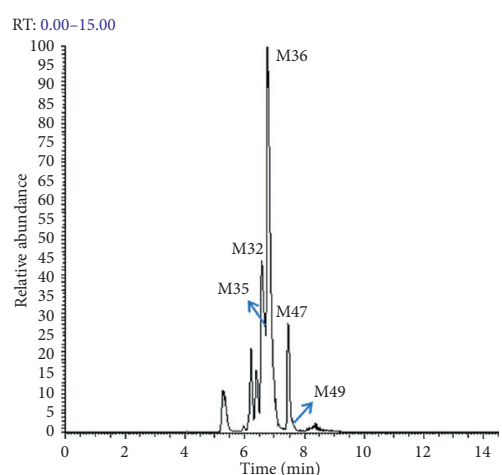

(c)

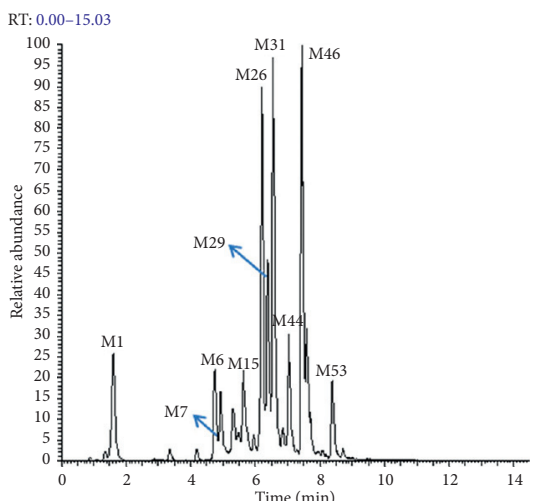

(f)

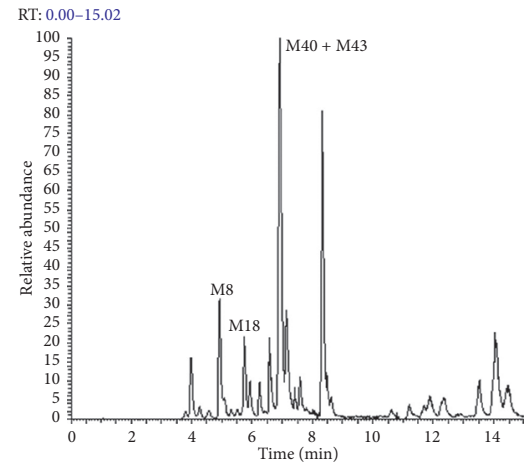

(i)

Figure 4: High-resolution extracted ion chromatograms of phillyrin metabolites (A-E) for negative ion mode and (F-J) for positive ion mode): (a) $m / z$ 339.2035, 417.1179, 451.1057, 507.2225, and 579.2072; (b) $m / z$ 261.1146, 271.0602, 315.0865, 437.0901, 453.0850, and 519.1498; (c) $\mathrm{m} / z$ 271.1329, 357.1332, 377.0689, 533.1652, and 547.1809; (d) $\mathrm{m} / \mathrm{z} 329.1021,333.1327,345.0968,359.1490,375.1074$, and 409.0588; (e) $\mathrm{m} / z$ 331.1177, 343.1177, and 347.1126; (f) $\mathrm{m} / z$ 298.0962, 305.1772, 315.1227, 341.1384, 377.1953, and 393.1543; (g) $\mathrm{m} / z$ 231.1404, 331.0811, 355.1541, and 492.1687; (h) $\mathrm{m} / z$ 273.1486, 285.0759, and 557.1993; (i) $\mathrm{m} / z$ 317.0657, 331.1178, 333.1332, and 371.1489; and $(\mathrm{j}) \mathrm{m} / \mathrm{z} 281.1173,295.0964,313.1070,317.1384,357.1332,373.1281$, and 373.1646. 
The metabolite M40 with a retention time of $6.87 \mathrm{~min}$ showed $[\mathrm{M}+\mathrm{H}]^{+}$ion at $m / z \quad 317.0657 \quad\left(\mathrm{C}_{16} \mathrm{H}_{13} \mathrm{O}_{7}\right.$, $-1.04 \mathrm{ppm})$. The DPI at $\mathrm{m} / z 133$ was $56 \mathrm{Da}$ (2CO) higher than $\mathrm{m} / z 77$ (phenyl), and $m / z 121$ was $44 \mathrm{Da}(\mathrm{CO}+\mathrm{O}$ ) higher than $m / z 77$. It was presumed that the original fivemembered ring portion has $\mathrm{C}=\mathrm{O}$ formation. According to the DPI at $m / z 109$, it was speculated that $2 \mathrm{OH}$ existed in the benzene ring moiety.

The metabolite M47 was eluted at $7.47 \mathrm{~min}$, which had $[\mathrm{M}-\mathrm{H}]^{-}$ion at $m / z 357.1332\left(\mathrm{C}_{20} \mathrm{H}_{21} \mathrm{O}_{6}, 3.94 \mathrm{ppm}\right)$. In the ESI-MS $^{n}$ spectrum, the DPIs produced by the cleavage of M47, such as $m / z 191,177,151,137$, and 123 , indicated that the two benzene rings underwent substitution reactions with diverse groups $\left(2 \mathrm{OCH}_{3}, \mathrm{OH}+\mathrm{OCH}_{3}\right)$, respectively. At the same time, the NLFs were $30 \mathrm{Da}\left(\mathrm{CH}_{2} \mathrm{O}\right.$, from $\mathrm{m} / z 357$ to $\mathrm{m} /$ $z 327)$ and $54 \mathrm{Da}\left(\mathrm{C}_{4} \mathrm{H}_{6}\right.$, from $\mathrm{m} / z 177$ to $\left.\mathrm{m} / z 123\right)$, it could be inferred that the two benzene rings were mutually connected through a five-membered ring and a double bond. Besides, it was known from the molecular formula that it was difficult to ascertain the substitution site of one $\mathrm{OH}$.

The metabolite M48 was eluted at $7.54 \mathrm{~min}$, and $[\mathrm{M}+\mathrm{H}]^{+}$ion was generated at $\mathrm{m} / z 331.0181\left(\mathrm{C}_{17} \mathrm{H}_{15} \mathrm{O}_{7}\right.$, $-0.54 \mathrm{ppm})$. The DPI at $m / z 162$ was $69 \mathrm{Da}\left(\mathrm{C}_{4} \mathrm{H}_{5} \mathrm{O}\right)$ higher than $\mathrm{m} / z 93$ (hydroxybenzene, $\mathrm{C}_{6} \mathrm{H}_{5} \mathrm{O}$ ), thereby confirming that the five-membered ring has undergone dehydrogenation to form a double bond. According to the molecular formula, in addition to the presence of $2 \mathrm{OH}$ in both benzene rings, the substitution site of $2 \mathrm{OH}$ could not be identified.

The metabolites M8 and M11 with retention times of $4.91 \mathrm{~min}$ and $5.08 \mathrm{~min}$, respectively, produced the same $[\mathrm{M}-\mathrm{H}]^{-}$ion at $m / z 331.1177\left(\mathrm{C}_{18} \mathrm{H}_{19} \mathrm{O}_{6}\right.$, error $\left.\leq \pm 5.00 \mathrm{ppm}\right)$. In their ESI-MS ${ }^{n}$ spectra, the NLFs were $30 \mathrm{Da}$ (from $\mathrm{m} / z$ 333 to $\mathrm{m} / z$ 303) and $28 \mathrm{Da}$ (from $\mathrm{m} / z 303$ to $\mathrm{m} / z 275$ ); this indicated that there was only one five-membered ring in the molecular structure. Further, product ions such as $\mathrm{m} / z 109$ and $m / z \quad 123$ stated the substituent groups $(2 \mathrm{OH}$, $\mathrm{OH}+\mathrm{OCH}_{3}$ ) on the two benzene rings.

The metabolite M10 was eluted at $4.96 \mathrm{~min}$ and showed $[\mathrm{M}-\mathrm{H}]^{-}$ion at $\mathrm{m} / z 333.1327\left(\mathrm{C}_{18} \mathrm{H}_{21} \mathrm{O}_{6}, 4.52 \mathrm{ppm}\right)$. DPIs generated by the continuous neutral loss of $\mathrm{CH}_{2} \mathrm{O}(30 \mathrm{Da})$ such as $\mathrm{m} / z 303$ and $\mathrm{m} / z 273$ indicated that both fivemembered rings were introduced into $\mathrm{H}_{2}$.

Metabolites M3, M4, and M5 eluted at $3.97 \mathrm{~min}$, $4.27 \mathrm{~min}$, and $4.58 \mathrm{~min}$, respectively, showed the same $[\mathrm{M}-\mathrm{H}]^{-}$ion at $m / z 347.1126\left(\mathrm{C}_{18} \mathrm{H}_{19} \mathrm{O}_{7}\right.$, error $\left.\leq \pm 4.50 \mathrm{ppm}\right)$. In the ESI-MS ${ }^{2}$ spectrum, the NLF was $30 \mathrm{Da}$ (from $\mathrm{m} / z 347$ to $m / z 317$ ), indicating the presence of a five-membered ring in the structural formula. The DPIs which appeared at $\mathrm{m} / z$ 163 and 193 further provided a basis for our inference. According to the DPIs such as $m / z 109,123$, and 137, the substitution of two benzene rings could be inferred. Since the substitution sites of the two hydroxyl groups were difficult to judge, M3, M4, and M5 were isomers.

The retention times of the metabolites M14 and M16 were $5.54 \mathrm{~min}$ and $5.69 \mathrm{~min}$, respectively, both of which produced $[\mathrm{M}-\mathrm{H}]^{-}$ion at $m / z 409.0588 \quad\left(\mathrm{C}_{18} \mathrm{H}_{17} \mathrm{O}_{9} \mathrm{~S}\right.$, error $\leq \pm 3.50 \mathrm{ppm})$. It was $42 \mathrm{Da}$ lower than $\mathrm{M} 42$, presumably owing to the loss of $3 \mathrm{CH}_{2}$. DPIs at $\mathrm{m} / z 329$ and $\mathrm{m} / z$ 80 provided strong evidence for this inference. Thus both
M14 and M16 were M42 demethylated products, except that the sulfonic acid groups had different binding positions.

Metabolites M27 and M30 were eluted at $6.31 \mathrm{~min}$ and $6.54 \mathrm{~min}$ and showed $[\mathrm{M}+\mathrm{H}]^{+}$ions at $\mathrm{m} / z \quad 357.1332$ $\left(\mathrm{C}_{20} \mathrm{H}_{21} \mathrm{O}_{6}, \quad-1.19 \mathrm{ppm}\right)$ and $m / z \quad 357.1332\left(\mathrm{C}_{20} \mathrm{H}_{21} \mathrm{O}_{6}\right.$, $-2.90 \mathrm{ppm})$, respectively. In the ESI-MS ${ }^{2}$ spectrum of both, the NLF was $112 \mathrm{Da}\left(\mathrm{C}_{6} \mathrm{H}_{8} \mathrm{O}_{2}\right.$, from $\mathrm{m} / z 189$ to $\left.\mathrm{m} / z 77\right)$, so a double bond was introduced in the five-membered ring. However, DPI was generated at $m / z 137$ in the ESI-MS ${ }^{n}$ spectrum of M30, and it was inferred that the bismethoxyphenyl group was present, and M27 did not have this group, so M27 $(\mathrm{Clog} P, 1.14)$ and $\mathrm{M} 30(\mathrm{Clog} P, 1.17)$ were isomers.

The metabolite M34 with a retention time of $6.65 \mathrm{~min}$ showed $[\mathrm{M}-\mathrm{H}]^{-}$ions at $m / z 359.1490\left(\mathrm{C}_{20} \mathrm{H}_{23} \mathrm{O}_{6}, 3.16 \mathrm{ppm}\right)$. The DPI at $m / z 344$ in the ESI-MS ${ }^{2}$ spectrum generated $\mathrm{m} / z$ 284 by loss of $2 \mathrm{CH}_{2} \mathrm{O}$, and then the DPIs such as $m / z 192$ and $m / z 178$ could assume that hydrogenation $\left(+2 \mathrm{H}_{2}\right)$ occurred in both five-membered rings and there was one molecular double bond. Further, based on the DPI at $m / z 122$, the functional groups on the two benzene rings could be deduced.

The retention times of the metabolites M13 and M19 were $5.30 \mathrm{~min}$ and $5.93 \mathrm{~min}$, respectively, and the same $[\mathrm{M}-\mathrm{H}]^{-}$ion was produced at $m / z 375.1074\left(\mathrm{C}_{19} \mathrm{H}_{19} \mathrm{O}_{8}\right.$, error $\leq \pm 4.00 \mathrm{ppm})$. In their ESI-MS ${ }^{2}$ spectra, the NLFs were $28 \mathrm{Da}(\mathrm{CO}$, from $\mathrm{m} / z 375$ to $\mathrm{m} / z 347)$ and $60 \mathrm{Da}\left(2 \mathrm{CH}_{2} \mathrm{O}\right.$, from $m / z 347$ to $m / z 287$ ), respectively. From this, it was presumed that there was a five-membered ring with a double bond and a dimethoxyphenyl group in the structural formula. Combined with the DPIs such as $m / z 137,109$, and the degree of unsaturation, the structural formula could be inferred. However, the positions of the three hydroxyl groups were still unidentifiable, and M13 and M19 were positional isomers.

The metabolite $\mathrm{M} 6$ possessed $[\mathrm{M}+\mathrm{H}]^{+}$ion at $\mathrm{m} / \mathrm{z}$ $393.1543\left(\mathrm{C}_{20} \mathrm{H}_{25} \mathrm{O}_{8},-8.33 \mathrm{ppm}\right)$ with a retention time of $4.75 \mathrm{~min}$. In the ESI-MS ${ }^{2}$ spectrum of M6, the DPI at $\mathrm{m} / z$ 393 was $93 \mathrm{Da}$ higher than $\mathrm{m} / z 300$, presumably due to the neutral loss of hydroxybenzene. At the same time, the DPI at $\mathrm{m} / z 300$ was $60 \mathrm{Da}$ higher than $\mathrm{m} / z 240$ and $28 \mathrm{Da}$ higher than $m / z 272$, and it was presumed that NLFs were $2 \mathrm{CH}_{2} \mathrm{O}$ $(60 \mathrm{Da})$ and $2 \mathrm{CH}_{2}(28 \mathrm{Da})$, respectively. Based on the information obtained, we could conclude that the structural formula of M6 contained hydroxybenzene and dimethoxyphenyl groups, and two of the five-membered rings were hydrogenated to open the ring. The DPIs at $m / z 216,246$, and 361 further confirmed the above judgment, and the substitution sites of three other hydroxyl groups could not be determined.

M24, M28, and M41 showed the same $[\mathrm{M}-\mathrm{H}]^{-}$ion at $\mathrm{m} / \mathrm{z}$ $437.0901\left(\mathrm{C}_{20} \mathrm{H}_{21} \mathrm{O}_{9} \mathrm{~S}\right.$, error $\left.\leq \pm 3.00 \mathrm{ppm}\right)$, and they were eluted at $6.14 \mathrm{~min}, 6.32 \mathrm{~min}$, and $6.88 \mathrm{~min}$, respectively. Their molecular weight was $14 \mathrm{Da}$ lower than that of M42, so they were inferred to be the demethylation products of M42. In the ESI-MS ${ }^{2}$ spectrum, the three metabolites had the same DPIs, such as $m / z 357,151,137$, and 80 , which proved that their benzene rings had identical substituents $\left(2 \mathrm{OCH}_{3}, 2 \mathrm{OH}\right)$. Because the substituents on the benzene rings and the sulfo 
(- $\mathrm{HSO}_{3}$ ) substitution site were different, M24, M28, and M41 were positional isomers [34].

The retention time of the metabolite M25 showing $[\mathrm{M}-\mathrm{H}]^{-}$ion at $m / z 453.0850\left(\mathrm{C}_{20} \mathrm{H}_{21} \mathrm{O}_{10} \mathrm{~S}, 2.62 \mathrm{ppm}\right)$ was $6.16 \mathrm{~min}$. Because its molecular weight was $16 \mathrm{Da}$ higher than M41, it can be speculated that M25 is the oxidation product of M41. The DPIs retrieved from M25's ESI-MS ${ }^{n}$ spectrum, such as $m / z 373,97$, and 80 , unexpectedly upheld the above guess.

The metabolite M59 was eluted at $26.48 \mathrm{~min}$ and showed $[\mathrm{M}-\mathrm{H}]^{-}$ion at $m / z 339.2035\left(\mathrm{C}_{15} \mathrm{H}_{31} \mathrm{O}_{8},-3.67 \mathrm{ppm}\right)$. Based on the molecular formula and the calculated degree of unsaturation, M59 was presumed to be a compound in which an alkane containing 15 carbon atoms was replaced by eight hydroxyl groups. Also, the DPIs and NLFs shown in the ESI-MS ${ }^{n}$ spectrum could prove this conclusion.

The metabolite M52 was detected at $8.34 \mathrm{~min}$, which produced $[\mathrm{M}+\mathrm{H}]^{+}$ion at $\mathrm{m} / z \quad 373.1646 \quad\left(\mathrm{C}_{21} \mathrm{H}_{25} \mathrm{O}_{6}\right.$, $-3.47 \mathrm{ppm})$. In the ESI-MS ${ }^{n}$ spectrum of M52, through various information, it could be undoubtedly identified as the parent compound of phillygenin $[31,35,36]$.

The metabolite M23 produced $[\mathrm{M}-\mathrm{H}]^{-}$ion at $m / z 417.1179$ $\left(\mathrm{C}_{21} \mathrm{H}_{21} \mathrm{O}_{9}, 3.67 \mathrm{ppm}\right)$, and its retention time was $5.98 \mathrm{~min}$. In the ESI-MS ${ }^{2}$ spectrum, the NLF was $176 \mathrm{Da}$ (from $\mathrm{m} / \mathrm{z} 417$ to $\mathrm{m} / \mathrm{z} 241$ ), and the unsaturated glucuronide group was presumed to be lost, and the DPI at $m / z 175$ confirmed this. The DPIs at $\mathrm{m} / z 121$ and $\mathrm{m} / z 103$ indicated that the benzene ring was substituted by two methyl groups, so the substitution position of one methyl group could not be determined.

The metabolite M7 was eluted at $4.84 \mathrm{~min}$ and showed $[\mathrm{M}+\mathrm{H}]^{+}$ion at $m / z 377.1953\left(\mathrm{C}_{16} \mathrm{H}_{25} \mathrm{O}_{10}, 1.56 \mathrm{ppm}\right)$. In the ESI-MS ${ }^{2}$ spectrum, NLF was $134 \mathrm{Da}$ (from $\mathrm{m} / z 377$ to $\mathrm{m} / \mathrm{z}$ 243 ), and it was presumed to be a derivative of glucose $\left(\mathrm{C}_{5} \mathrm{H}_{10} \mathrm{O}_{4}\right)$. According to the DPIs at $\mathrm{m} / z 172$ and $\mathrm{m} / z 72$, the substitution position of four hydroxyl groups could be inferred, of which three hydroxyl groups reacted with the benzene ring, and the other hydroxyl group was substituted on the alkane.

3.4.3. Identification of Metabolites Based on Enterolactone. The metabolite M50 was eluted at $7.63 \mathrm{~min}$, and the $[\mathrm{M}+\mathrm{H}]^{+}$ion was displayed at $\mathrm{m} / z 231.1140\left(\mathrm{C}_{16} \mathrm{H}_{23} \mathrm{O}\right.$, $-0.35 \mathrm{ppm})$. From the DPIs in the ESI-MS ${ }^{2}$ spectrum of M50, such as $m / z 135,107$, and 93, it could be inferred that a hydroxy group was substituted on the benzene ring. Then it could be speculated that another benzene ring had undergone an additional reaction, which itself had been introduced with four hydrogen atoms.

The metabolite M45 produced $[\mathrm{M}+\mathrm{H}]^{+}$ion at $\mathrm{m} / \mathrm{z}$ $273.0759\left(\mathrm{C}_{15} \mathrm{H}_{13} \mathrm{O}_{5},-0.70 \mathrm{ppm}\right)$ with a retention time of $7.36 \mathrm{~min}$. In the ESI-MS ${ }^{2}$ spectrum, the DPIs at $\mathrm{m} / z 123$ and $\mathrm{m} / \mathrm{z} 95$ indicated the substitution of two benzene rings $\left(\mathrm{OH}+\mathrm{OCH}_{3}, \mathrm{OH}\right)$. At the same time, the NLF was $28 \mathrm{Da}$ (from $\mathrm{m} / z 151$ to $\mathrm{m} / \mathrm{z} 123$ and from $\mathrm{m} / \mathrm{z} 255$ to $\mathrm{m} / \mathrm{z} 227$ ), and it was speculated that there were two ketone groups between the two benzene rings.

The metabolite M51 was eluted at $7.83 \mathrm{~min}$ and showed $[\mathrm{M}+\mathrm{H}]^{+}$ion at $m / z 281.1173\left(\mathrm{C}_{18} \mathrm{H}_{17} \mathrm{O}_{3},-2.07 \mathrm{ppm}\right)$. In the
ESI-MS $^{n}$ spectrum, the DPIs at $m / z 263,235,133$, and 107 fully demonstrated the double bond formation in the two 5membered ring structures. Besides, the NLF was $16 \mathrm{Da}$ (from $\mathrm{m} / z 149$ to $\mathrm{m} / z$ 133), indicating that there was still a hydroxyl group whose substitution site was unknown.

The metabolite M37 with a retention time of $6.77 \mathrm{~min}$ showed $[\mathrm{M}+\mathrm{H}]^{+}$ion at $\mathrm{m} / z \quad 285.0759 \quad\left(\mathrm{C}_{16} \mathrm{H}_{13} \mathrm{O}_{5}\right.$, $-1.30 \mathrm{ppm})$. Based on the DPIs located in the ESI-MS ${ }^{2}$ spectrum, such as $m / z 161$ and $m / z 85$, it can be inferred that three consecutive keto groups were present. Meanwhile, the continuous loss of $\mathrm{O}$ atom $(16 \mathrm{Da})$ indicated that there are two hydroxyl groups in the other benzene ring.

The metabolite M20, which was eluted at $5.93 \mathrm{~min}$, had $[\mathrm{M}+\mathrm{H}]^{+}$ion at $\mathrm{m} / z 295.0964\left(\mathrm{C}_{18} \mathrm{H}_{15} \mathrm{O}_{4},-1.51 \mathrm{ppm}\right)$. According to the continuous neutral loss of $\mathrm{CO}(28 \mathrm{Da})$ (from $\mathrm{m} / z 277$ to $\mathrm{m} / z 249$ and from $\mathrm{m} / z 249$ to $\mathrm{m} / z 221$ ) and the DPI at $m / z 186$, it could be presumed that there were two double bonds in the two five-membered ring structure. Furthermore, the continuous loss of water molecules (18 Da) further proved the existence of dihydroxyphenyl.

The retention time of the metabolite $\mathrm{M} 1$ was $1.61 \mathrm{~min}$, which showed $[\mathrm{M}+\mathrm{H}]^{+}$ion at $m / z 298.0962\left(\mathrm{C}_{19} \mathrm{H}_{12} \mathrm{ON}_{3}\right.$, $-2.81 \mathrm{ppm})$. In the ESI-MS ${ }^{2}$ spectrum of M1, the NLFs were $26 \mathrm{Da}$ (from $\mathrm{m} / z 189$ to $\mathrm{m} / z 163$ to $\mathrm{m} / \mathrm{z} 137$ ), and it was presumably caused by the continuous loss of $\mathrm{CN}$. What is more, the substitution site where a hydroxyl group should also exist in the structural formula could not be determined. Therefore, there were three cyano groups and one hydroxyl group in the structural formula.

The metabolite M21 was eluted at $5.94 \mathrm{~min}$ and showed $[\mathrm{M}+\mathrm{H}]^{+}$ion at $\mathrm{m} / \mathrm{z} 313.1070\left(\mathrm{C}_{18} \mathrm{H}_{17} \mathrm{O}_{5},-1.73 \mathrm{ppm}\right)$. According to the DPIs in the ESI-MS ${ }^{2}$ spectrum, such as $\mathrm{m} / z$ $277,249,123,161$, and 173 , could be presumed the substitution of two benzene rings $\left(\mathrm{OH}+\mathrm{OCH}_{3}, \mathrm{OH}\right)$ could be presumed and the existence of a five-membered ring and two double bonds between them. Also, according to the molecular formula, it was known that there was still one hydroxyl substitution site that could not be identified.

Metabolite M53 has a retention time of $8.39 \mathrm{~min}$, which had $[\mathrm{M}+\mathrm{H}]^{+}$ion at $m / z 315.1227\left(\mathrm{C}_{18} \mathrm{H}_{19} \mathrm{O}_{5},-9.27 \mathrm{ppm}\right)$. In the ESI-MS ${ }^{2}$ spectrum of M53, the DPIs at $m / z 93,109,167$, and 189 could fully clarify the substituents $(2 \mathrm{OH}, \mathrm{OH})$ on the two benzene rings. At the same time, the NLF was $60 \mathrm{Da}$ (from $\mathrm{m} / z 315$ to $\mathrm{m} / \mathrm{z} 255$ ), which was presumed to be due to the continuous loss of $\mathrm{CH}_{2} \mathrm{O}$, so there were two fivemembered rings in the structural formula.

The metabolite $\mathrm{M} 9$ was eluted at $4.95 \mathrm{~min}$, and it showed $[\mathrm{M}+\mathrm{H}]^{+}$ion at $\mathrm{m} / z \quad 317.1384\left(\mathrm{C}_{18} \mathrm{H}_{21} \mathrm{O}_{5}, 0.16 \mathrm{ppm}\right)$. Analogous to the above, based on the DPIs in the ESI-MS spectrum, such as $m / z 123,149,151,163$, and 175 , the substituents $\left(\mathrm{OH}+\mathrm{OCH}_{3}\right)$ on the two benzene rings were presumed. It was inferred from the degree of unsaturation that the linear alkane between the two benzene rings undergone a dehydrogenation reaction to form a double bond. At the same time, it could be known from the molecular formula that another $\mathrm{OH}$ substitution site could not be determined.

The metabolites M15, M26, M29, M31, and M46 were eluted at 5.62, 6.21, 6.38, 6.55, and $7.44 \mathrm{~min}$, respectively, and 


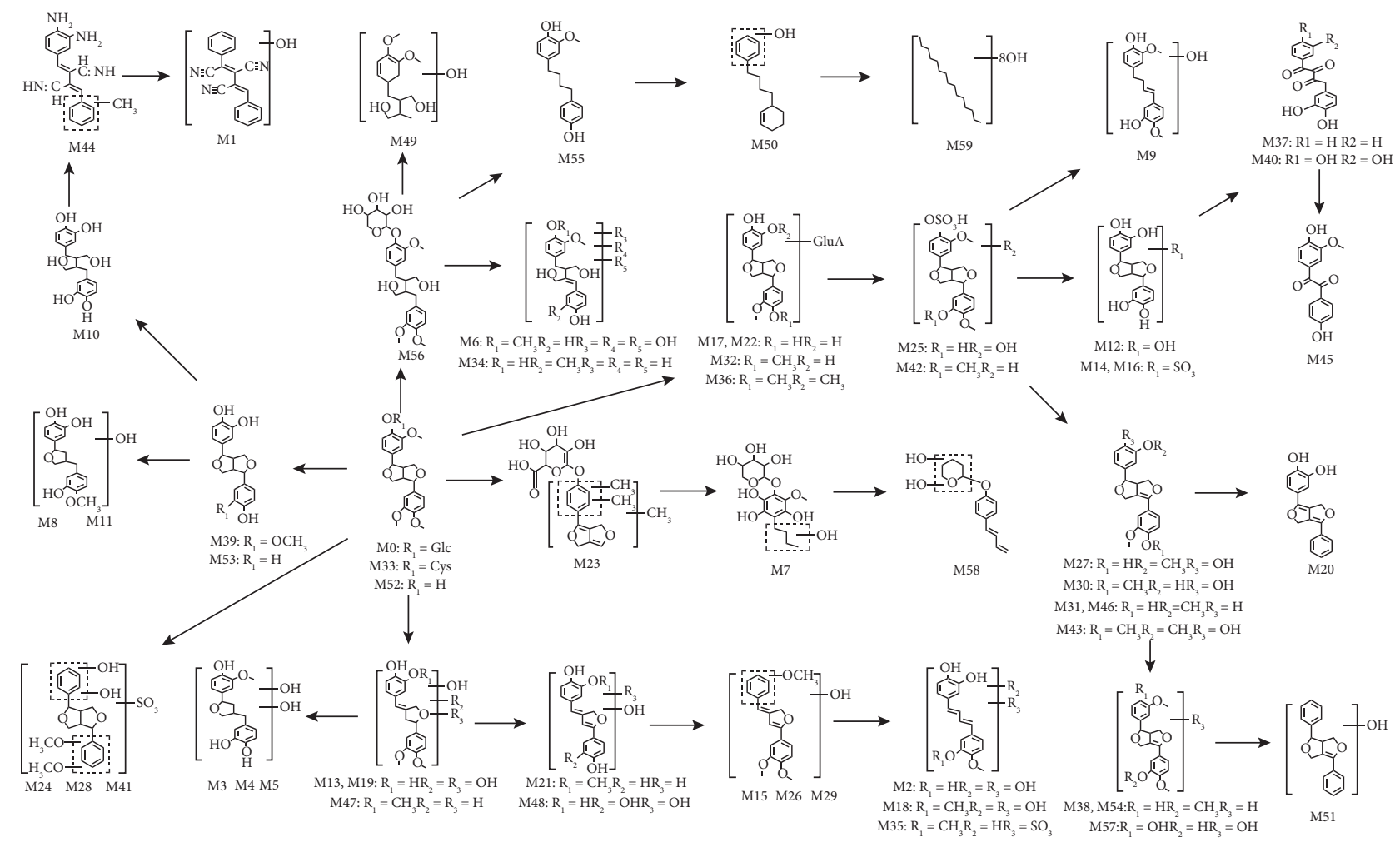

FIGURE 5: The proposed phillyrin metabolic patterns in vivo.

they all showed the same $[\mathrm{M}+\mathrm{H}]^{+}$ion at $\mathrm{m} / z 341.1384$ $\left(\mathrm{C}_{20} \mathrm{H}_{21} \mathrm{O}_{5}\right.$, error $\left.\leq \pm 1.50 \mathrm{ppm}\right)$. Among them, in the ESI-MS ${ }^{2}$ spectra of M15, M26, and M29, DPIs at $m / z 137$ and $m / z 187$ indicated the presence of dimethoxyphenyl and methoxyphenyl. At the same time, NLFs were $28 \mathrm{Da}$ (from $\mathrm{m} / z 291$ to $\mathrm{m} / z 263$ ) and $70 \mathrm{Da}$ (from $\mathrm{m} / z 341$ to $\mathrm{m} / z 271$ ), which proved that there were a five-membered ring and two double bonds between the two benzene ring structures. Additionally, it was difficult to determine the position of one hydroxyl group. Therefore, it was inferred that the three metabolites were isomers because the substitution positions of methoxy and hydroxyl groups were different. However, in the ESI-MS ${ }^{n}$ spectra of $\mathrm{M} 31$ and $\mathrm{M} 46$, the substituents $\left(\mathrm{OH}+\mathrm{OCH}_{3}\right.$, $\mathrm{OCH}_{3}$ ) on the two benzene rings could be presumed based on the DPIs at $m / z 123,151$, and 161 . Meanwhile, the NLFs were $30 \mathrm{Da}\left(\mathrm{CH}_{2} \mathrm{O}\right.$, from $\mathrm{m} / z 341$ to $\left.\mathrm{m} / z 311\right)$ and $28 \mathrm{Da}$ (CO, from $\mathrm{m} / z 311$ to $\mathrm{m} / z 283$ ), and the existence of two five-membered rings and the formation of a double bond were further deduced. Because the position of the methoxy group was difficult to determine, M31 and M46 were positional isomers.

The retention time of the metabolite $\mathrm{M} 12$ was $5.15 \mathrm{~min}$, and it had $[\mathrm{M}-\mathrm{H}]^{-}$ion at $m / z 345.0969\left(\mathrm{C}_{18} \mathrm{H}_{17} \mathrm{O}_{7}\right.$, 4.20 ppm). DPIs in the ESI-MS ${ }^{2}$ spectrum, such as $m / z 109$ and 137, revealed the structure of two benzene rings $(2 \mathrm{OH}$, $2 \mathrm{OH})$. The neutral loss of $60 \mathrm{Da}\left(2 \mathrm{CH}_{2} \mathrm{O}\right)$ resulted in the formation of DPI at $m / z 285$, indicating that the two fivemembered rings remained unchanged. Also, there was still no known substitution site for a hydroxyl group, so M12 was a demethylation and oxidation product of phillygenin.

The metabolite M35 was eluted at $6.69 \mathrm{~min}$ and produced $[\mathrm{M}-\mathrm{H}]^{-}$ion at $m / z 377.0689\left(\mathrm{C}_{18} \mathrm{H}_{17} \mathrm{O}_{7} \mathrm{~S}, 3.69 \mathrm{ppm}\right)$. In the
ESI-MS ${ }^{2}$ spectrum, the NLF was $81 \mathrm{Da}\left(\mathrm{HSO}_{3}\right)$, which was presumably due to the neutral loss of the sulfo group. At the same time, the DPIs at $m / z 107$ and $\mathrm{m} / z 189$ revealed the existence of the substituents on the two benzene rings $\left(2 \mathrm{OCH}_{3}, 2 \mathrm{OH}\right)$ and the presence of two double bonds between the benzene rings.

The metabolite M49, which was eluted at $7.61 \mathrm{~min}$, showed $[\mathrm{M}-\mathrm{H}]^{-}$ion at $m / z \quad 271.1329 \quad\left(\mathrm{C}_{14} \mathrm{H}_{23} \mathrm{O}_{5}\right.$, $4.68 \mathrm{ppm})$. In the ESI-MS ${ }^{n}$ spectrum, the NLF was $60 \mathrm{Da}$ (from $m / z 271$ to $m / z 211$ ), and it was inferred that the two five-membered rings undergo hydrogenation $(+\mathrm{H} 4)$ to open the ring. The DPIs at $m / z 151$ and $m / z 165$ proved that the benzene ring had an addition reaction $\left(\mathrm{H}_{2}\right)$ and was replaced by $2 \mathrm{OCH}_{3}$. Another $\mathrm{OH}$ substitution site was challenging to identify.

The metabolite M55 with a retention time of $8.49 \mathrm{~min}$ showed $[\mathrm{M}+\mathrm{H}]^{+}$ion at $m / z 273.1486\left(\mathrm{C}_{17} \mathrm{H}_{21} \mathrm{O}_{3}, 0.80 \mathrm{ppm}\right)$. The DPIs in the ESI-MS ${ }^{2}$ spectrum, such as $m / z 179,137$, and 95, clarified the structure of the two benzene rings $\left(\mathrm{OH}+\mathrm{OCH}_{3}, \mathrm{OH}\right)$. Based on the established molecular formula, it could be inferred that the fabric between two benzene rings was a linear alkane containing four carbon atoms.

3.5. Proposed Metabolic Pathways of Phillyrin. In our study, a total of 60 metabolites (including the prototype compound) were detected and identified in rats that were orally administered phillyrin. The proposed metabolic pathways of forsythiaside are shown in Figure 5. The main biological reactions of phillyrin in rats included the following types, such as hydrogenation, methylation, hydroxylation, 
glucuronidation, sulfonation, carbonylation, ammoniation, dehydrogenation, demethylation, and ring cleavage and their composite reactions. Also, some extraordinary products had been discovered, such as carbon-nitrogen unsaturated bonds formed in M1 and M44. Moreover, the metabolites M49, M50, and M59, which were generated by hydrogenation or cleavage of benzene, had never been reported before.

\section{Conclusions}

After oral administration of phillyrin to rats, metabolites in plasma, urine, and feces of rats were studied comprehensively. Its innovation lay in the use of a new comprehensive strategy to screen and identify 60 in vivo metabolites of phillyrin. Firstly, the combination of UHPLC and Q-Exactive MS overcame many of the shortcomings of traditional triple quadrupole mass spectrometry, and the extremely high resolution could significantly eliminate the interference of the sample matrix. Secondly, the formation of the data set mainly depended on a variety of data mining methods, such as high extracted ion chromatogram (HEIC), diagnostic product ion (DPI), neutral loss filtering (NLF), and isotope pattern filtering (IPF). Finally, accurate qualitative identification of compounds could be achieved based on the precise relative molecular mass of each chromatographic peak in the mass spectrum, the ion fragment information of the secondary mass spectrum, the fragmentation rule of the mass spectrum, and the chromatographic retention time. The results showed that the primary biological reactions of phillyrin in vivo included methylation, hydrogenation, sulfonation, glucuronidation, demethylation, dehydrogenation, ring cleavage, and their composite reactions. Among them, the biological activity of some specific metabolites was unknown. In summary, this study provided vital information to the research field of phillyrin metabolism and had important value significance for studying the mechanism of action of phillyrin and monitoring of drug content.

\section{Data Availability}

The data used to support the finding of this study are available from the corresponding author upon request.

\section{Conflicts of Interest}

The authors have declared no conflicts of interest.

\section{Acknowledgments}

This work was financially supported by Chinese Pharmacopoeia Commission (no. 2018Y007).

\section{References}

[1] Y. Cheng, X. Liang, L. Feng et al., "Effects of phillyrin and forsythoside a on rat cytochrome $\mathrm{P} 450$ activities in vivo and in vitro," Xenobiotica; the Fate of Foreign Compounds in Biological Systems, vol. 47, no. 4, pp. 297-303, 2017.

[2] T. DongLiu, Y. Li, and L. Zhang, "Nine different chemical species and action mechanisms of pancreatic lipase ligands screened out from Forsythia suspensa leaves all at one time," Molecules, vol. 22, no. 5, p. 795, 2017.

[3] Z. Han, X.-L. Lei, H. Zhang et al., "Evaluating the safety of forsythin from Forsythia suspensa leaves by acute and subchronic oral administration in rodent models," Asian Pacific Journal of Tropical Medicine, vol. 10, no. 1, pp. 47-51, 2017.

[4] D. Liu, X. He, and Q. He, "Combining use of Phillyrin and autophagy blocker alleviates laryngeal squamous cell carcinoma via AMPK/mTOR/p70S6K signaling," Bioscience Reports, vol. 39, no. 6, 2019.

[5] L. Yang, X. Zhou, W. Huang et al., "Protective effect of phillyrin on lethal LPS-induced neutrophil inflammation in zebrafish," Cellular Physiology and Biochemistry, vol. 43, no. 5, pp. 2074-2087, 2017.

[6] X.-Y. Fang, Q.-J. Li, H.-M. Zhang et al., "Protective effects of phillyrin against influenza a virus in vivo," Archives of Pharmacal Research, vol. 39, no. 7, pp. 998-1005, 2016.

[7] T. Zhang, W. Tian, H. Yan, G. Shao, and G. Xie, "Protective effects of phillyrin on $\mathrm{H}_{2} \mathrm{O}_{2}$-induced oxidative stress and apoptosis in PC12 cells," Cellular and Molecular Neurobiology, vol. 34, no. 8, pp. 1165-1173, 2014.

[8] W.-t. Shao, Y.-c. Wu, X.-x. Xie et al., "Phillyrin attenuates LPS-induced pulmonary inflammation via suppression of MAPK and NF- $\kappa \mathrm{B}$ activation in acute lung injury mice," Fitoterapia, vol. 90, pp. 132-139, 2013.

[9] X. Zhou, F. S. A. Saadeldeen, L. Xu et al., "The mechanism of phillyrin from the leaves of Forsythia suspensa for improving insulin resistance," BioMed Research International, vol. 2019, Article ID 3176483, 7 pages, 2019.

[10] P. Kong, L. Zhang, Y. Guo, Y. Lu, and D. Lin, "Phillyrin, a natural lignan, attenuates tumor necrosis factor $\alpha$-mediated insulin resistance and lipolytic acceleration in 3T3-L1 adipocytes," Planta Medica, vol. 80, no. 11, pp. 880-886, 2014.

[11] H. B. Lu, G. G. Sui, and X. Y. Lu, "Phillyrin lowers body weight in obese mice via the modulation of PPAR/-ANGPTL 4 pathway," Obesity Research \& Clinical Practice, vol. 12, no. 1, pp. 71-79, 2018.

[12] J. Wang, G. Chen, Q. Zhang et al., "Phillyrin attenuates osteoclast formation and function and prevents LPS-induced osteolysis in mice," Frontiers in Pharmacology, vol. 10, p. 1188, 2019.

[13] R. S. Silveira, B. A. Rocha, J. L. Rodrigues et al., "Rapid, sensitive and simultaneous determination of 16 endocrinedisrupting chemicals (parabens, benzophenones, bisphenols, and triclocarban) in human urine based on microextraction by packed sorbent combined with liquid chromatography tandem mass spectrometry (MEPS-LC-MS/MS)," Chemosphere, vol. 240, 2020.

[14] H. Ložnjak, H. Striegel, X. De la Garza et al., "Ultra performance liquid chromatography-Q exactive orbitrap/mass spectrometry-based lipidomics reveals the influence of nitrogen sources on lipid biosynthesis of mortierella alpina," Food Chemistry, vol. 305, 2020.

[15] L.-L. Yang, Y. Yao, X.-H. Hu et al., "Pharmacokinetics and tissue distribution of gingerols and shogaols from ginger (zingiber officinale rosc.) in rats by UPLC-Q-exactiveHRMS," Talanta, vol. 207, 2020.

[16] X. Ma, Q. Chen, H. Tang et al., “"Ultra performance liquid chromatography-Q exactive orbitrap/mass spectrometrybased lipidomics reveals the influence of nitrogen sources on lipid biosynthesis of mortierella alpine," Journal of Agricultural and Food Chemistry, vol. 67, no. 39, pp. 10984-10993, 2019. 
[17] Y. Zhang, F. Cui, Y. Guo et al., “"Pharmacokinetics and tissue distribution of gingerols and shogaols from ginger (zingiber officinale rosc.) in rats by UPLC-Q-exactive-HRMS," Biomedicine \& Pharmacotherapy, vol. 24, no. 3, p. 512, 2019.

[18] X. Jiang, Q. He, H. Hou et al., "Targeted lipidomics profiling of marine phospholipids from different resources by UPLC-QExactive Orbitrap/MS approach," Journal of Chromatography B, vol. 1096, pp. 107-112, 2018.

[19] Z. Tian, Y. Jiang, Y. Li et al., "Evaluation of the anti-hypertensive effect of Tengfu Jiangya tablet by combination of UPLC-Q-exactive-MS-based metabolomics and iTRAQbased proteomics technology," Biomedicine \& Pharmacotherapy, vol. 100, pp. 324-334, 2018.

[20] L. Li, Y. Wang, Y. Xiu et al., "Chemical differentiation and quantitative analysis of different types of Panax genus stemleaf based on a UPLC-Q-exactive orbitrap/MS combined with multivariate statistical analysis approach," Journal of Analytical Methods in Chemistry, vol. 2018, Article ID 9598672, 16 pages, 2018.

[21] Z. Yang and Y. You, "P36 Proteomics studies on effect of Xiao-Xu-Ming decoction on cerebral ischemia rat by UPLCQ-Exactive technology," Biochemical Pharmacology, vol. 139, pp. 137-138, 2017.

[22] E. Rathahao-Paris, S. Alves, L. Debrauwer et al., “"An efficient data-filtering strategy for easy metabolite detection from the direct analysis of a biological fluid using Fourier transform mass spectrometry," Rapid Communications in Mass Spectrometry, vol. 31, no. 6, pp. 485-494, 2017.

[23] Y.-M. Yang, Y.-Y. Shi, Q. Yao et al., "Automatic peak detection coupled with multivariate curve resolution-alternating least squares for peak resolution in gas chromatography-mass spectrometry," Journal of Chromatography A, vol. 177, 2020.

[24] Y. Lv, F. Feng, B. Nie et al., "High throughput identification of pentacyclic triterpenes in Hippophae rhamnoides using multiple neutral loss markers scanning combined with substructure recognition (MNLSR)," Talanta, vol. 205, 2019.

[25] C. Zhang, A. Zhang, L. R. Raphaël et al., "Automatic peak detection coupled with multivariate curve resolution-alternating least squares for peak resolution in gas chromatography-mass spectrometry," Journal of Chromatography A, vol. 1601, pp. 300-309, 2019.

[26] W. Arias, Z. Li, Q. Li et al., "“A target-group-change couple with mass defect filtering strategy to identify the metabolites of "Dogel ebs" in rats plasma, urine and bile," Journal of Separation Science, vol. 42, no. 21, pp. 3302-3310, 2019.

[27] Y. Huang, W. McCann, C. Raphaël, Z. Wang, and J. Zhang, "Rapid visualization of chemically related compounds using Kendrick mass defect as a filter in mass spectrometry imaging," Analytical Chemistry, vol. 91, no. 20, pp. 13112-13118, 2019.

[28] W. Wang, J. Shang, M. Li et al., "A two-step ultra-highperformance liquid chromatography-quadrupole/time of flight mass spectrometry with mass defect filtering method for rapid identification of analogues from known components of different chemical structure types in Fructus GardeniaeFructus Forsythiae herb pair extract and in rat's blood," Molecules, vol. 23, no. 1, p. 151, 2018.

[29] F.-X. Liang, Z.-N. Zhao, X.-Y. Wang et al., "A comprehensive screening and identification of genistin metabolites in rats based on multiple metabolite templates combined with UHPLC-HRMS analysis," Molecules, vol. 23, no. 8, p. 1862, 2018.

[30] L.-H. Zhang, Y.-X. Zhang, C. Jia, X.-H. Gong, and X.-G. Zheng, "Metabolic profile of phillyrin in rats obtained by UPLC-Q-TOF-MS," European Journal of Drug Metabolism and Pharmacokinetics, vol. 30, no. 6, pp. 913-922, 2016.

[31] Y.-G. Gong, B.-Y. Yao, J. Qin, D. Wang, Q. Yang, and H.-X. Kuang, "Isolation and identification of phase I metabolites of phillyrin in rats," Fitoterapia, vol. 97, pp. 92-97, 2014.

[32] H. Li, X. Shan, P. Meng et al., "Metabolic profile of phillyrin in rats obtained by UPLC-Q-TOF-MS," Journal of Chromatography A, vol. 1563, pp. 99-123, 2018.

[33] H. Cao, L. Zhang, and J. Peng, "Determination of phillyrin in rat plasma by high performance liquid chromatography-tandem mass spectrometry and its application to a pharmacokinetic study," Latin American Journal of Pharmacy, vol. 31, no. 2, pp. 207-213, 2012.

[34] C. Zhang, Z.-H. Xie, Z.-F. Tang et al., "A combination of representative compounds, metabolism platform and diagnostic extraction strategy for characterization of metabolites of Shuang-Huang-Lian oral liquid in vivo by ultra-performance liquid chromatography coupled with time-of-flight mass spectrometry," Journal of Pharmaceutical and Biomedical Analysis, vol. 155, pp. 216-234, 2018.

[35] L. Wang, Y. Li, C. Peng et al., "Determination of phillygenin in rat plasma by high-performance liquid chromatography and its application to pharmacokinetic studies," European Journal of Drug Metabolism and Pharmacokinetics, vol. 38, no. 3, pp. 201-207, 2013.

[36] Y. G. Xia, B. Y. Yang, J. Liang et al., "Optimization of simultaneous ultrasonic-assisted extraction of water-soluble and fat-soluble characteristic constituents from Forsythiae Fructus Using response surface methodology and high-performance liquid chromatography," Pharmacognosy Magazine, vol. 10, no. 39, pp. 292-303, 2014. 